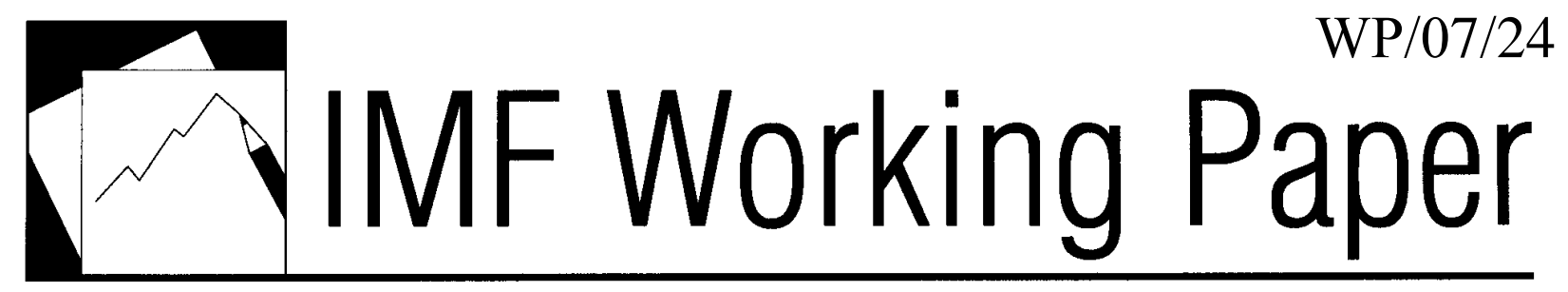

\title{
What Explains Germany's Rebounding Export Market Share?
}

Stephan Danninger and Fred Joutz 



\title{
IMF Working Paper
}

European Department

\section{What Explains Germany's Rebounding Export Market Share?}

\author{
Prepared by Stephan Danninger and Fred Joutz ${ }^{1}$
}

Authorized for distribution by Bob Traa

February 2007

\begin{abstract}
This Working Paper should not be reported as representing the views of the IMF. The views expressed in this Working Paper are those of the author(s) and do not necessarily represent those of the IMF or IMF policy. Working Papers describe research in progress by the author(s) and are published to elicit comments and to further debate.
\end{abstract}

Germany's export market share increased since 2000, while most industrial countries experienced declines. This study explores four explanations and evaluates their empirical contributions: (i) improved cost competitiveness, (ii) ties to fast growing trading partners, (iii) increased demand for capital goods, and (iv) regionalized production of goods (e.g. offshoring). An export model is estimated covering the period 1993-2005. The dominant factors explaining the increase in market share are trade relationships with fast growing countries and regionalized production in the export sector. Improved cost competitiveness had a comparatively smaller impact. There is no conclusive evidence of increased demand for capital goods.

JEL Classification Numbers:C22, F41

Keywords: International trade, export

Authors’ E-Mail Addresses: sdanninger@imf.org; bmark@gwu.edu

\footnotetext{
${ }^{1}$ Fred Joutz is Professor at George Washington University in Washington DC.
} 


\section{Contents}

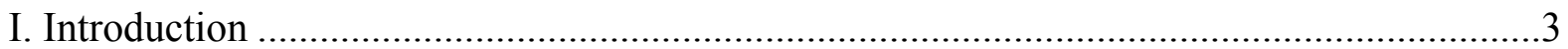

II. Potential Explanations and Stylized Facts ................................................................4

1.Cost Competitiveness Through Wage Moderation ..............................................

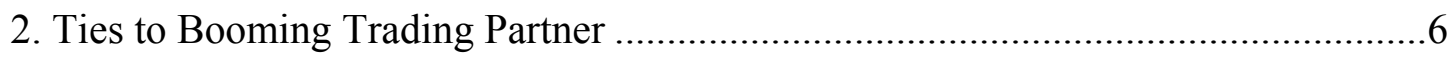

3. Meeting Global Investment Demand ............................................................ 6

4. Regionalization of Production Processes ..........................................................

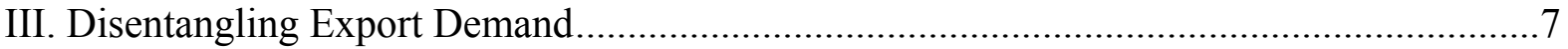

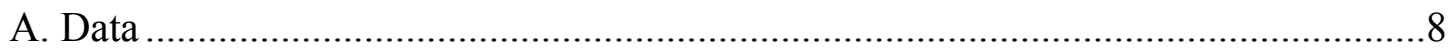

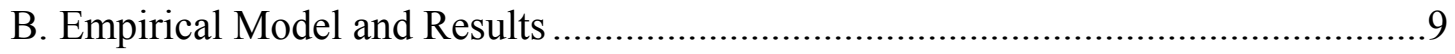

IV. Quantifying the Contributions to Gains in Export Market Share ...................................13

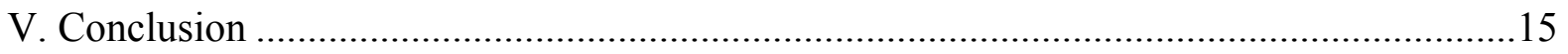

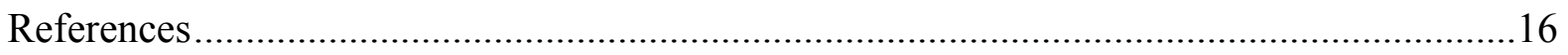

Appendices

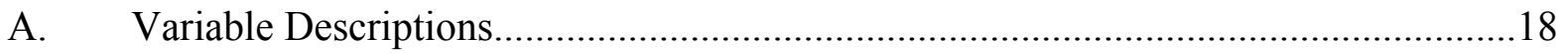

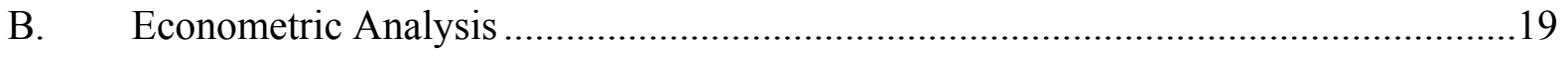




\section{INTRODUCTION ${ }^{2}$}

Germany's export sector has become its main source of economic growth. Since 1999 about 80 percent of real GDP growth was generated from net exports (Figure 1). Real exports have grown by more than 7 percent per annum since 2000 on the back of growing trade volumes with both traditional European partners and emerging economies (Table 1). ${ }^{3}$ Since 2000 Germany also began to regain export market share, especially among industrial countries and the euro area (Figure 2). ${ }^{4}$

Empirical studies of German export behavior have detected changes in the determinants of German exports. Since the 1990s the impact of relative prices on exports is smaller than before unification, possibly related to a shift in pricing behavior or product mix (Stahn 2006). There is also evidence that structural factors related to European integration boosted export growth (Stephan 2002).

The duration of Germany's high export growth rates has generated much speculation about its sources (Economic Council 2004). This paper discusses four hypotheses and attempts to quantify their relative importance. The four hypotheses are: (i) improved cost competitiveness through moderate collective wage agreements since the mid 1990s; (ii) ties to fast growing trading partners as a result of a desirable product mix or long-standing traderelationships; (iii) increased export demand for capital goods as a response to a global rise in investment activity, and (iv) regionalized production patterns through off-shoring of production to lower cost countries, partly a result of European economic integration (Sinn 2006).

The proposed explanations encompass traditional determinants of German exports, namely relative prices and export demand of trading partners. The analysis goes beyond this standard approach and also tests the relevance of other variables, in particular whether exports were affected by the global investment cycle or by off-shoring of production processes to other countries. The paper also quantifies the relative contribution of the relevant empirical determinants since 2000.

By assessing the relative importance of the four approaches, prospects for continued export growth and economic activity can be gauged. A large impact of regained cost competitiveness signals a structural improvement and a continuation of export growth. In contrast, if the recent export surge is driven primarily by cyclical factors, such as a global investment boom, the benefits may prove temporary.

\footnotetext{
${ }^{2}$ The authors are grateful to Ercument Tulun and Toh Kuan for assistance in accessing the IMF WEO database. The paper has benefited from discussions with Bob Traa, Hans W Sinn, Martin Werding, and comments by seminar participants of the IMF's EUR seminar series and the IFO seminar in Munich.

${ }^{3}$ Import growth has been strong despite weak domestic demand and low consumption growth.

${ }^{4}$ By 2005, Germany became the official world goods export champion if measured in nominal \$US values. German Statistical Office (2006).
} 
The empirical results confirm previous findings in the literature. The analysis is based on the estimation of a multivariate system, which reduces to a stable, conditional single equation error-correction model for export demand. Estimates of the long-term export elasticities for relative prices and activity in partner countries are consistent with findings from other studies (Stahn 2006).

The analysis shows that recent export growth can be traced back to the ability of German exporters to meet global demand and to exploit new production and cost cutting opportunities from offshoring activities. The estimated export models show a unitary export elasticity with respect to overall import demand of trading partners. In other words, Germany has been able to take advantage of the rapid growth of global markets as found for instance by Everaert and others (2005). The analysis also provides empirical support for the claim that German exports increased as a result of a regional division of labor in the production of goods (Sinn 2006, Hummels and others 2001). These two factors explain about 60 percent of the faster increase of German exports since 2000 vis a vis industrial countries. Changes in relative prices, measured by the real effective exchange rate, on the other hand contributed comparatively little despite prolonged wage moderation. This is not surprising given the strong nominal effective appreciation of the euro since 2000. There is no conclusive evidence of faster export growth due to higher investment expenditures of trading partners and the demand for capital goods.

The paper comprises three sections. Part II discusses the four hypothesis for Germany's export growth and presents some stylized facts. In Part III a time-series model of German goods exports is developed using quarterly data since 1993. Long-term determinants of export growth are identified and their relative contribution to the growth in export market share is computed. The final section concludes.

\section{Potential Explanations and Stylized Facts}

Since the early 1990s the German economy has been exposed to several economic shocks, which all have likely affected its export performance. These shocks were: German unification and an associated increase of labor costs; a global labor supply shock through the market entry of emerging countries with low labor costs (e.g., India, China), a global income shift towards oil exporting countries, and European economic integration which opened new export markets and allowed new production processes to emerge.

Most explanations for Germany's rapidly rising exports are in one way or another representing adjustment processes triggered by these changes in the external environment. The two most well known examples are "wage moderation" (IMF 2001) and the "Bazaar" effect (Sinn 2005). Wage moderation refers to efforts to regain cost competitiveness by reducing comparative labor costs through low wage growth. The "Bazaar" effect describes the response of enterprises to new international production opportunities, which may have turned Germany into a trading hub, hence the reference to a Bazaar. Other explanations are linked to the entrance of new players in global trade and their high demand for capital goods, or a more pronounced cyclical upswing in Germany's trading partners. 
This section discusses four hypotheses explaining Germany's increase in export market share together with stylized facts which heuristically underpin the arguments. Definitions of the main variables are given in Appendix A. The proposed explanations are pursued more formally in the next section. Other possible answers also may have played a role, but were not pursued. ${ }^{5}$

\section{Cost competitiveness through wage moderation}

German unification resulted in a steep increase in wage costs mainly from pressures to close the wage gap between new and old Länder and from tax increases to cover the cost of extending the welfare state. The resulting loss of cost competitiveness and economic restructuring led to high unemployment. By the mid 1990s a period of restrained wage setting followed, referred to as wage moderation, to reverse these developments (Blanchard and Phillipon 2004). During this period, wages and salary growth lagged behind productivity — the cost-neutral margin — in almost every year (Ulman, Gerlach, and Giuliano 2005).

From an international perspective the relevant measure capturing cost competitiveness is the real effective exchange rate at unit labor costs (REERulc) in industry. ${ }^{6}$ Wage costs per unit of output began to decrease sharply in 1995 and remained at a low level since 2000 despite a significant nominal effective appreciation of the euro (Figure 3). The main factor responsible for this adjustment was muted wage growth in industry (Carlin 2001, ECB 2005). Average hourly nominal wage growth declined continuously and hovers since 2003 around 1-2 percent (Figure 4). Labor productivity growth in manufacturing was positive but lagged behind the OECD average. Hence many observers concluded that cost competitiveness has been a main source for export growth and even argued that a return to more normal wage growth was possible and would help strengthen domestic demand. The role of (REERulc) in explaining exports is formally explored in the empirical section.

\footnotetext{
${ }^{5}$ E.g. trade activities within the euro area could have also been spurred by tax fraud (VAT carousel trade). ${ }^{6}$ Improved price competitiveness could have also been helped by cuts in profit margins, which is however unlikely given the large increase in profit shares in the corporate sector since the early 2000 s.
} 


\section{Ties to booming trading partner}

A second hypothesis relies on Germany's ability to penetrate growing export markets. German exporters have well established trade links to emerging market countries. Prior to 2000 Germany's share of exports to Asian countries was larger than that of France and Italy.

Table 1 shows that in 2005 exports to Asia reached 11 percent of total exports on the back of a strong acceleration of exports to China and India. Similarly, traditional ties to oil exporting countries may have allowed Germany to benefit more than its competitors from a recycling of Petro dollars. As Table 1 shows, exports to oil exporters have grown rapidly, although their share in total exports is still small.

A more comprehensive view of export demand by German partner countries can be obtained from an index of trade share weighted import growth of German partner countries (GDEM). ${ }^{7}$ Figure 4 compares $G D E M$ with global trade growth (i.e. growth of global real imports) and the trade-share weighted import growth of all industrial countries. This comparison suggests that after 2000 Germany experienced relatively higher export demand than industrial countries in aggregate. Global export demand expanded even faster, reflecting the rapid increase of trade with emerging market countries, especially China. It is therefore plausible that part of the increase of Germany's export market share among industrial countries could have been due to its ties to fast growing economies. The role of GDEM in explaining exports is explored in the empirical section below.

\section{Meeting global investment demand}

Another potential explanation for Germany's rapid export growth is a structural shift in goods demanded. The global upturn since 2000 was characterized by increasing investment activity. Germany traditionally exports capital goods and could therefore have benefited more than other countries from an increase in the demand for these export goods. ${ }^{8}$

A cursory look at the data suggests that exports in particular of capital goods may have increased. Global growth since 2000 was characterized by a strong rebound in investment activity especially in emerging markets (Figure 5). This global trend can be compared to investment growth in Germany's trading partners, assuming that growth of investment

\footnotetext{
${ }^{7}$ This variable was computed from data of the IMF's World Economic Outlook database.

${ }^{8}$ Another reason why exports of investment goods may have picked up are growing incentives to further specialize in capital intensive activities. This argument has been put forward by Sinn (2006) and is based on a standard trade model with labor market rigidities (Davies 1998). In this model the existence of a binding wage floor (e.g. through high welfare benefits) can drive a wedge between domestic and international relative factor prices. As a result, the economy adjusts through further specialization in the capital intensive sector which creates unemployment in equilibrium. This process leads to more international trade, but also an inefficient allocation of factors. Sinn argues that this development could have taken place in Germany. European economic integration and a global labor supply shock have both decreased the price for unskilled labor and driven a wedge between German relative factor prices and international prices. Germany's increased exports of capital intensive goods could therefore be interpreted as a response to a global labor supply shock. Thus, a slowdown in global trade could have a relatively strong negative growth impact on the German economy.
} 
activity is linked to a rise of capital goods imports. Investment growth of Germany's trading partners weighed by export trade shares (Ginv) has been higher than in industrial countries as a whole, but not by much. A more disaggregated view of exports into capital goods exports and other types offers however no clear evidence: the share of capital goods among overall exports in Germany appears to have been stagnant thus suggesting that there was no faster acceleration in the exports of capital goods compared to other goods (Figure 6). The role of GINV is explored in more detail in the next section.

\section{Regionalization of production processes}

A final explanation is based on increasing cross-border division of labor to take advantage of lower production costs of labor intensive processes outside Germany. For Germany, this process has been documented by Sinn (2005) and the Economic Council (2004). Since the mid 1990s, the share of imported inputs in the export sector increased from 28 percent to over 42 percent in 2005 (Figure 7) while at the same time domestic value added in the export sector (DomVA) decreased. As an increasing share of industrial production began to be placed abroad, trade volumes increased between German exporters and its subsidiaries or suppliers abroad. To the extent that Germany has taken advantage of this opportunity at a faster pace than other industrial countries, it could have improved productivity and increased its export market share.

Several studies have documented the incentives for outsourcing and off-shoring and their effect on trade. Figure 8 reproduces estimates by Marin (2005) on relative ULC in countries outside of Germany. An empirical link between the relocation of production and the trade of goods was established by a recent Bundesbank (2006) study. Increased outbound FDI to new EU member countries from Germany appears complementary to an increases in both imports from and exports to these countries. The next section assesses whether there is a link between trends in Germany's DomVA and exports.

To conclude, the four presented hypotheses are not necessarily competing explanations. Most likely, all of them have contributed to some degree to Germany's surge in exports. It is therefore an empirical question to identify their relative contributions. It is also important to note that they have different implications for a continuation of export growth and longer-term economic outlook. Greater cost competitiveness, either through wage moderation or through regionalization of production processes, should have a longer lasting positive effect on export prospects. Also, strong preferences for German products $(\mathrm{Gdem})$ could signal strength in penetrating growth markets for instance through a desirable product mix. In contrast, if exports were growing primarily because of a first mover advantage or global investment activity, then these developments may come sooner or later to an end, as either the global cycle matures or competitors enter growth markets.

\section{Disentangling EXPORT DEMAND}

The goal of this section is to assess empirically the relative contribution of the four presented hypotheses in explaining Germany's export growth. To this end, we develop several time series models of German goods exports utilizing information on relative cost 
competitiveness, export demand, capital goods demand, and the structure of production in the export sector.

Using quarterly national accounts data beginning in 1992, a number of well specified econometric models are identified using standard inference and estimation methods. We then interpret parameter estimates and assess whether they are consistent with theory. Robustness tests are carried out to determine the stability of the empirical models. We are interested in whether the interaction between domestic and international shocks with exports changed the dynamics and determinants of exports. In a final step, we compute the economic impact of the various variables in explaining growth of Germany's export market share compared to industrial countries between 2000-05.

\section{A. Data}

The empirical analysis explores cointegrating relationships between five of the variables discussed above: volume of goods export $(\mathrm{Xgr})$, the real effective exchange rate based on unit labor costs $(R E E R u l c)^{9}$, and global import demand $(\mathrm{Gdem})$, global investment activity of Germany's trading partners (Ginv), and the share of domestic valued added in industry $(D o m V A)$.

Germany's bulk of exports come from the manufacturing sector. The relevant measure for cost competitiveness is hence the real effective exchange rate based on unit labor costs in industry rather than unit labor costs economy wide. The comparison of unit labor costs is quite common and has been applied in a number of recent studies (Bundesbank 1988, Hooper 1998).

Empirical measures of demand by partner countries for German exports are reviewed by Stahn 2006. We use a trade weighted index of import volume growth by Germany's trading partners $(\mathrm{Gdem})$ as opposed to sales or manufacturing output. The advantage of this variable is that the estimated elasticity allows inferences about developments of Germany's market share. Also the results can be more readily compared with other studies..$^{10}$

The global investment activity variable Ginv proxies for the demand for capital goods. The index used to measure this demand is computed as the trade-share weighted investment activity of trading partners and hence, indirectly measures import demand for investment goods. A possible drawback is that this measure overlaps with the import demand measure Gdem.

\footnotetext{
${ }^{9}$ An increase in REERulc denotes a real appreciation and means a loss of competitiveness. Between 1992 and 1996 cost competitiveness decreased by roughly 30 percent followed by a 25 percent real depreciation thereafter. The real effective exchange rate stabilized in 2001 despite a significant appreciation of the Euro vis a vis the US dollar indicating further decreases in relative unit labor costs.

${ }^{10}$ A value of 1 indicates a constant market share or that exports from Germany to its trading partners increase in line with world trade volume. A value smaller than one indicates a loss in global export market share.
} 
The share of domestic value added in industry attempts to capture the ongoing process of offshoring production processes. The observed decline in value added in the exporting sector is a reflection of an increase in the share of imported intermediate goods (Sinn 2006). In the empirical analysis we use value added in industry as a proxy for increased regionalization of production processes.

Details on the variables used in the study are presented in Appendix A. All models are based on quarterly observations between 1993Q1 and 2005Q4. Data for unified Germany prior to 1993 were either missing or have been dropped due to unification related fluctuations. Table 2 provides summary statistics. Figure 9 shows plots of all variables used in the analysis.

\section{B. Empirical Model and Results}

We consider four alternative models to examine the hypotheses. We considered a fifth model which is a combination of the alternative models, but could not develop an adequately specified statistical model for it. The variables included in each model are presented in the table below.

\begin{tabular}{lcccc}
\hline \hline & REER_ulc & Gdem & Ginv & Dom_VA \\
\hline \hline Model A: Standard Export Demand & $\mathrm{X}$ & $\mathrm{X}$ & & \\
$\begin{array}{l}\text { Model B: } \text { Export Demand Model Driven by } \\
\begin{array}{l}\text { Domestic Investment and Foreign Capital } \\
\text { Goods }\end{array}\end{array}$ & $\mathrm{X}$ & & $\mathrm{X}$ & \\
Model $\boldsymbol{C}$ : Combination of A and B. & $\mathrm{X}$ & $\mathrm{X}$ & $\mathrm{X}$ & \\
$\begin{array}{l}\text { Model D: } \text { Export Demand Model Driven by } \\
\text { Regionalization of Production Processes }\end{array}$ & $\mathrm{X}$ & $\mathrm{X}$ & & $\mathrm{X}$ \\
$\begin{array}{l}\text { Model } \boldsymbol{E}: \text { Model D plus Domestic } \\
\text { Investment and Foreign Capital Goods }\end{array}$ & $\mathrm{X}$ & $\mathrm{X}$ & $\mathrm{X}$ & $\mathrm{X}$ \\
\hline \hline
\end{tabular}

\section{Specification of the VAR Model}

The test for a long-run or equilibrium relationship for German exports demand starts with the estimation of vector autoregression model, VAR or system. The VAR can be generally specified as:

$$
\begin{aligned}
& {\left[\begin{array}{c}
\text { Exports }_{t} \\
\text { REERu }_{t} \\
\text { Demand }_{t} \\
\text { Other }_{t}
\end{array}\right]=\Pi(L)\left[\begin{array}{c}
\text { Exports }_{t-1} \\
\text { REER }_{t-1} \\
\text { Demand }_{t-1} \\
\text { Other }_{t-1}
\end{array}\right]+B\left[\begin{array}{c}
\text { constant } \\
\text { Cseasonals }_{t}
\end{array}\right]+\left[\begin{array}{c}
\varepsilon_{1, t} \\
\varepsilon_{2, t} \\
\varepsilon_{3, t} \\
\varepsilon_{4, t}
\end{array}\right]} \\
& \text { where } \Pi(L)=\Pi_{1} L+\Pi_{2} L^{2}+\Pi_{3} L^{3}+\ldots+\Pi_{p} L^{p}
\end{aligned}
$$


All variables have been transformed into natural logarithms. Constant and centered seasonal terms are included in each equation, because we use seasonally unadjusted data for German exports. The error terms are assumed to be white noise and can be contemporaneously correlated. The expression $\Pi(L)$ is a lag polynomial operator indicating that $\mathrm{p}$ lags of each price is used in the VAR. The individual $\Pi_{\mathrm{i}}$ terms represent a $5 \times 5$ matrix of coefficients at the ith lag.

A general to specific approach was employed in the estimating the model. First, a simple unrestricted VAR was estimated and evaluated for statistical fit and stability. Second, the lag structure of the VAR is determined. The evaluation for statistical fit and stability is repeated. Then we test for equilibrium or cointegrating relation(s) among the variables. Next, based on the existence of cointegration, we test hypotheses on the relation(s) and interpret the models. Results from ADF test are presented Table 2.B and discussed in appendix B.

\section{VAR Model Specification, Estimation, and Testing for Cointegration}

There are four tables (Tables 3A-D to 6A-D) presented for each test corresponding to the above models A, B, C, and D. The number of lags to use in model at the beginning is unknown. The selection methodology starts with an initial maximum of $p$ lags which are assumed to be more than necessary. Residual diagnostic tests like normality, serial correlation, and heteroscedasticity are conducted and the VAR system is tested for stability. The goal is to obtain results that appear close to the assumption of white noise residuals. A large number of lags are likely to produce an over-parameterized model. However, any econometric analysis needs to start with a statistical model of the data generating process. Parsimony is achieved by testing for the fewest number of lags that can reasonably explain the dynamics in the data system.

\section{Lag Length Selection and Model Stability Tests}

The selection criteria for the appropriate lag length of the unrestricted VAR models employ

$\chi^{2}$ test(s) and F-tests. Tables 3.A-D contain results for the former and Tables 4.A-D include results for the latter. The lag length in all model ranged between 3-5 quarters. F-tests performed on all models suggested generally a greater lag length. In the end, a system with a 5-lags unrestricted VAR was chosen, because individual equations had serial correlation problems. To confirm stability of the basic model recursive stability analysis was carried out. All four models passed 1-step Chow and N-down Chow tests at 5 percent. For a detailed discussion on lag length and model stability see appendix B and Tables 3 A-D, 4 A-D, and 5 A-D. The results recursive model stability tests are reported in appendix B as well and Figures 10 and 11.

\section{The Cointegration Analysis of the Vector Autoregression Model}

In this section the Johansen procedure is applied to test for the presence of cointegration. The VAR model in levels can be linearly transformed into one in first differences. 
$\left[\begin{array}{c}\Delta \text { Exports }_{t} \\ \Delta \text { REERu }_{t} \\ \text { Demand }_{t} \\ \Delta \text { Other }_{t}\end{array}\right]=\Pi\left[\begin{array}{c}\text { Exports }_{t-1} \\ \text { REERu }_{t-1} \\ \text { Demand }_{t-1} \\ \text { Other }_{t-1}\end{array}\right]+\Gamma(L)\left[\begin{array}{c}\Delta \text { Exports }_{t-1} \\ \Delta \text { REERu }_{t-1} \\ \Delta \text { Demand }_{t-1} \\ \Delta \text { Other }_{t-1}\end{array}\right]+B\left[\begin{array}{c}\text { constant } \\ \text { Cseasonals }_{t}\end{array}\right]+\left[\begin{array}{c}\varepsilon_{1, t} \\ \varepsilon_{2, t} \\ \varepsilon_{3, t} \\ \varepsilon_{4, t}\end{array}\right]$

where $\Pi(L)=\Pi_{1} L+\Pi_{2} L^{2}+\Pi_{3} L^{3}+\ldots+\Pi_{p} L^{p}$

$$
\varepsilon \square(0, \Omega), \quad \Gamma_{1}=-\Pi_{2}, \Pi=\Pi_{1}+\Pi_{2}-I
$$

The crux of the Johansen test is to examine the mathematical properties of the $\Pi$ matrix in 1.2 , which contains important information about the dynamic stability of the system.

Intuitively, the $\Pi$ matrix in equation 1.1 contains the expression relating the levels of the endogenous variables in the system.

Engle and Granger (1987) demonstrate the one-to-one correspondence between cointegration and error correction models. Cointegrated variables imply an error correction (ECMs) representation for the econometric model and, conversely, models with valid ECMs impose cointegration. Evaluating the number of linearly independent equations in $\Pi$ is done by testing for the number of non-zero characteristic roots, or eigenvalues, of the $\Pi$ matrix, which equals the number of linearly independent rows. ${ }^{11}$ The matrix can be rewritten as the product of two full column vectors, $\Pi=\alpha \beta^{\prime}$.

The matrix $\beta$ ' is referred to as the cointegrating vector and $\alpha$ as the weighting elements for the rth cointegrating relation in each equation of the VAR. The vector $\beta^{\prime} Y_{t-1}$ is normalized on the variable of interest in the cointegrating relation and interpreted as the deviation from the "long-run" equilibrium condition. In this context, the column $\alpha$ represents the speed of adjustment coefficients from the "long-run" or equilibrium deviation in each equation. If the coefficient is zero in a particular equation, that variable is considered to weakly exogenous and the VAR can be conditioned on that variable. Weak exogeneity implies that the beta terms or long-run equilibrium relations do not provide explanatory power in a particular equation. If that is true, then valid inference can be conducted by dropping that equation from the system and estimating a conditional model.

Using the model specifications A-D the unrestricted VAR was estimated using ordinary least squares. The results of the Johansen cointegration test are presented in Table 6.A-D. We found that there appears to be a single cointegrating relation in Models A, C, and D, but not for Model B. We rejected the null of no cointegration or rank zero for three models, but could not do so in one. We test and attempt to interpret the relations as "equilibrium models" of German goods exports. The first standardized eigenvector or $\beta$ vector is normalized on

\footnotetext{
${ }^{11}$ The number of linearly independent rows in a matrix is called the rank.
} 
German exports. In model A and D weak exogeneity could not be rejected. Details are discussed in appendix B.

Long run relationships of models $A, C$, and $D$

The final standard export demand relation for model $\mathrm{A}$ is given by

$$
\begin{aligned}
& \text { Exports }_{t}=-0.42 \text { Real Effective Exchange Rate }{ }_{t}+1 \text { Global Export Demand }_{t} \\
& \text { Speed of Adjustment }=\alpha=-0.63
\end{aligned}
$$

The exchange rate elasticity is about 0.4 percent. Thus a 2.5 percent real appreciation in the Euro will reduce Germany's goods exports by one percent. The restriction of unit global demand elasticity could not be rejected. We found that global demand and the exchange rate could be treated as weakly exogenous. The speed of adjustment coefficient suggests that 85 percent of "disequilibrium" is corrected in four quarters. The empirical results confirm the basic expectations. Improved cost competitiveness and global growth have the correct signs and the model adjusts fairly rapidly to deviations from the "export fundamentals."

As a next step, we examine whether including investment activity in partner countries (trade weighted) improves the model fit. The intuition is that Germany, as an exporter of capital goods, benefits from investment activity abroad. We find that for this specification the export model $\mathrm{C}$ is given by:

$$
\begin{aligned}
& \text { Exports }_{t}=-0.27 \text { Real Effective Exchange Rate } \\
& t \\
& \text { Speed of Adjustment }=\alpha=-36\left(\text { Global Export Demand }_{t} / \text { Global Investment }_{t}\right)
\end{aligned}
$$

Again exchange rate elasticity has a negative sign and is a bit more inelastic $(0.27)$ suggesting a four percent real effective appreciation at unit labor costs in the Euro would result in a one per cent decline in German exports. The speed of adjustment coefficient suggests that 90 percent of "disequilibrium" is corrected in four quarters.

The cointegrating vector suggested that the coefficients for export demand growth and investment activity were of equal and opposite sign. We initially thought they would both be positive. The equal but opposite sign or differential hypothesis could not be rejected. There are three reasons for this puzzle. First, the result becomes clearer when we disaggregate this ratio by different regions. Increases in export demand from other European countries are negatively correlated with investment activity, and that investment growth in the US is not correlated with export demand from the US. Since these two regions have a large weight in the aggregate index, they may account for the opposite signs. Second, further analysis highlights another potential problem with the investment measure. Implicitly the investment index assumes the fraction of capital goods imported per investment unit is constant across countries. This assumption is too restrictive and unlikely to hold. In particular, the import demand for capital goods from fast growing emerging markets may have been underestimated. The net effect of the countervailing influences cannot be assessed with the current data. As a result we decided to omit the investment variable in the following 
specification. The puzzle remains, but could be addressed through regional analysis of exports (e.g. Stahn 2006).

The final export model that we explored augments the standard export model by the regionalization of the production processes hypothesis (model D). The regionalization hypothesis was approximated by the share of domestic value added in industry (Dom_VA) which declined throughout the sample period. The cointegrating relationship is given by

$$
\begin{aligned}
& \text { Exports }_{t}=-0.19 \text { Real Effective Exchange Rate }{ }_{t}+0.77 \text { Global Export Demand }_{t}-4.0 \text { Value Added }_{t} \\
& \text { Speed of Adjustment }=\alpha=-0.37
\end{aligned}
$$

The exchange rate elasticity is 0.19 and indistinguishable from the standard export demand model. The test that the global demand elasticity was unity could not be rejected. Domestic value added has a negative sign meaning that the decline in domestic value added improved export growth. A decline of domestic value added in industry by 1 percentage point in one year increases exports by 4 percent. This result is consistent with and tends to support Sinn's efficiency or Bazaar economy argument. However, we cannot determine the degree of the misallocation and its potential impacts on the economy. In a global marketplace competitive pressures will distribute the content of production to the most cost-efficient producers. The decline of value added is probably driven by larger imported inputs which have a positive effect on German exports and imports. The speed of adjustment in this model or return from a "disequilibrium" takes about 4 quarters.

\section{QUantifying The Contributions to Gains in Export MARKet Share}

The long-term relationship unearthed in model $\mathrm{D}$ are in a next step used to back out the relative contributions of the different variables to the increase of Germany's export market share relative to industrial countries. Industrial countries are the natural comparator for Germany and have therefore been chosen as a benchmark. As a starting year we chose 2000 when Germany began to increase its export market share.

To assess which factors are responsible for the increase in export market share, we first decompose predicted export growth into two components: one is the level of export growth that is needed to keep the export market share constant vis-à-vis industrial countries; and the remainder that is responsible for changes in the export market share. The quantitative contributions of the various variables explaining this latter component then reflect their relative weight in the increase of Germany's export market share.

Before we carry out this decomposition, we must first assess the model fit. If the estimated export models explain only a small fraction of overall export growth between 2000-05, then the decomposition is of limited value. The first line in Table 7 summarizes the model fit and the respective contributions of the individual variables. For the period 2000-05 model D predicts an average annual export growth rate of 5.0 percent. The actual growth rate was slightly higher (6.0) percent indicating that 83 percent of actual export growth can be explained by the fundamental variables. 
The respective model contributions of the variables Gdem, Reer $u$, and DomVA are reported in the columns to the right of the model results. The bulk of export growth, 3.9 percent, is explained by growth in global export demand. An additional 1.1 percent of export growth is explained by the other two variables Reer_u (0.11) and DomVA (0.97). The bazaar effect appears to explain about $15 \%-20 \%$ of total export growth.

We now make a crucial assumption that allows us to assess the relative contribution of the various variables in explaining the increase in export market share compared to industrial countries. We assume that for any industrial country global export demand can be broken into a component common to all industrial countries and a country specific component. The common component captures the demand for exports which keeps market shares unchanged. The country specific part explains changes in market share: a negative specific component would indicate a loss in market share relative to this group, a positive component gains in market share. By implication, the export growth explained by the other two variables (Reer_ulc, Gdem), and the residual (unexplained growth) would also contribute to changes in the export market share.

The middle two columns in Table 7 show the decomposition of Germany's export demand growth into the common and the country specific demand component. ${ }^{12}$ In both models the bulk of export growth is explained by the common components. From a total of 6.0 percent export growth roughly 3.2 percent ( 50 percent of model forecast) would have been necessary to maintain a constant export market share. The remainder can be attributed to the other variables (1.6 percent from country specific demand, Reer_ulc, GdemVA), and the rest comes from the residual (1.0 percent).

The relative contributions from the four components responsible for the change in export market share is reported in the third panel of Table 7. The German specific component and the decline in domestic value added account for the bulk of the increase with 25 and 35 percent respectively. Relative cost improvements only account for around 4 percent of the increase in export market share. The unexplained residual component accounts for another 36 percent.

The large contribution of the country specific demand is consistent with other findings (Everaert 2005) and confirm that German exporters are benefiting from growth in trading partners. The sizeable contribution of from a declining share of Dom_VA lends some empirical support for the Bazaar hypotheses proposed by Sinn (2006). It is also consistent with estimated trade effects of German outward FDI to the new EU member countries (Bundesbank 2006) and explains the limited spillovers of export to domestic employment and demand (Economic Council 2004).

\footnotetext{
${ }^{12}$ Data for export demand for industrial countries comes from the IMF WEO database and reflected trade weighted import demand for these countries. Since Germany is part of this group and its export demand could not be removed from the group average, the estimated of the common component has been biased upwards. As a result the country specific export demand component is biased downwards which underplays its role in explaining the increase in export market share.
} 
The small role of REER_ulc is surprising at a first glance given prolonged wage moderation. However, the influence of wage moderation on international cost competitiveness appears to be muted by the large effective nominal appreciation of the euro between 2000-05. If this offsetting exchange rate adjustment is taken into account, the small positive contribution of Reer_ $u$ to gains in export market share is actually quite remarkable.

\section{Conclusion}

Since 2000 Germany's export market share has gradually recovered. The paper reviews four different hypotheses explaining export growth and evaluates their relative contribution to the gain in export market share. They are: (i) regained cost competitiveness through wage moderation since the mid 1990s; (ii) ties to fast growing trading partners; (iii) increased export demand for capital goods in response to a global increase in investment activity, and

(iv) new regionalized production chains in the export sector, for instance, through off-shoring of labor intensive steps.

The long-term parameters estimated by the models are consistent with previous empirical findings in the literature. The econometric analysis identifies stable long-run relationships between export growth and variables which measure the proposed hypotheses. The estimates are then used to quantify the relative contribution of these factors to the observed market share increase. The dominant factors explaining the increase in export market share vis-à-vis industrial countries since 2000 are trade relationships with fast growing countries and a suggested trend to regionalized production in the export sector. Together they account for 60 percent of the faster export growth compared to other industrial countries.

Improved cost competitiveness played a comparatively smaller role in explaining the brisk export growth. The prolonged effort in containing costs through wage moderation was significant, but diluted by the appreciation of the euro. Cost competitiveness improved hence primarily vis-à-vis euro area countries and explains also the significant rise of Germany's export market share within the eurozone. There was no conclusive evidence of faster export growth due to higher investment expenditures of trading partners and the demand for capital goods. The delayed response of investment activity during the most recent upswing may have not allowed to capture this effect with current data.

An important contribution of the paper is its attempt to test whether Germany's export growth was linked to the emergence of new production chains (Marin 2005). Following a well known literature (e.g. Sinn 2005, 2006) the paper argued that the fall of value added in Germany's export sector reflects a growing share of traded intermediate inputs in the production process. From this perspective, the empirical link between value added and export growth can be viewed as evidence for a more decentralized production process. This interpretation also helps explain why the recent surge in exports did not translate into a significant employment growth in German industry (Becker and others 2005). While this finding is intuitively appealing, the empirical evidence is only indirect and further research is needed to confirm this result. 


\section{References}

Becker S. and K. Ekholm, R.Jaeckle and M.-A. Muender (2005), Location Choice and Employment Decisions: A Comparison of German and Swedish Multinationals, Cesifo WP 1374, January, Munich.

Blanchard, Olivier J. and Philippon, Thomas (2004), "The Quality of Labor Relations and Unemployment,” MIT Department of Economics Working Paper No. 04-25.

Bundesbank (2006) Determinanten der Leistungsbilanzentwicklung in den mittel- und osteuropäischen EU-Mitgliedsländern und die Rolle deutscher Direktinvestitionen, Monatsbericht Januar 2006, 17-36.

Bundesbank (1998), Effects of exchange rates on German foreign trade. Prospects under the conditions of the European monetary union. Monthly Reports, January 49-58.

Davies, Don (1998) Does European Unemployment Prop Up American Wages? National Markets and Global Trade, American Economic Review 88 478-494.

Carlin, W and Andrew Glyn, and John Van Reenan (2001), Export Market Performance of OECD Countries: An Empirical Examination of the Role of Cost Competitiveness, Economic Journal Vol. 111.

ECB (2005), Competitiveness and the Export Performance of the Euro Area, Occasional Paper Series No 30, June.

Lloyd Ulman, Knut Gerlach, and Paola Giuliano, "Wage Moderation and Rising Unemployment” (January 25, 2005). Institute of Industrial Relations. Institute of Industrial Relations Working Paper Series. Paper iirwps-110-05.

German Statistical Office (2006) Konjunkturmotor Export, Wiesbaden, Germany.

Economic Council (2004) Erfolge im Ausland Herausforderungen im Inland, Annual Report, Wiesbaden.

Everaert L. C Allard, M Catalan, and S. Sgherri (2005), France, Germany, Italy Spain, Explaining Differences in External Sector Performance among Large Euro Area Countries, IMF Country Report, SM 05/401, Washington DC

German Economic Council (2000), The Germany Economy in the Autumn 2000, Economic Bulletin, Vol. 37 No. 11, pp. 345-68, Springer.

Hooper P. and others (1998) Trade elasticities for G-7 countries. Board of Governors of the Federal Reserve System, International Finance Discussion Papers, No 609, April. 
Hummels D. and Jun Ishii, and Kei-Mu Yi (2001) The nature and growth of vertical specialization in world trade, Journal of International Economics, Vol. 54, 75-96.

IMF (2001): Country Report No. 01/203. Selected Euro-Area Countries: Rules-Based Fiscal Policy and Job-Rich Growth in France, Germany, Italy, and Spain, ch. III. Washington, D.C.: International Monetary Fund, November 2001.

IMF (2004), Germany Staff Report of the 2004 Article IV Consultation, SM 04/134, Washington DC.

Sinn H. W. (2005) Basar-Ökonomie Deutschland Exportweltmeister oder Schlusslicht, ifo Schnelldienst 58/6, Munich.

Sinn H. W. (2006): The Pathological Export Boom and the Bazaar Effect - How to Solve the German Puzzle, Ces-ifo WP 1708, April, Munich.

Stahn, K (2006) Has the Impact of Key Determinants of German Exports Changes? Results from Estimations of Germany's Intra euro-area and Extra-euro area Exports, Deutsche Bundesbank, Discussion Paper 07/2006.

Stephan, S. (2002) German Exports to the Euro area, DIW Discussion Paper 286, Berlin.

Strau $\beta$ H. (2004) Multivariate Cointegration Analysis of Aggregate Exports: Empirical Evidence for the United States, Canada, and Germany, Kiel Studies No 329, Kiel Institute for World Economics. 


\section{APPENDiX A. VARIABle Descriptions}

\section{XGR}

\section{Sample 1993Q1-2005Q4}

Total goods export volume (erg).

Base year 2000, quarterly 1993Q1-2005Q4, billions of Euros.

Source: German Federal Statistical Office.

\section{REER_ulc}

Real effective exchange rate based on relative unit labor costs in industry (ULC), Index $2000=100$

Source: International Financial Statistics (IFS)

Gdem (Germany's global export demand)

Export share weighted growth rates of real aggregate import volumes (ex/including oil) in Germany's trading partner countries transformed into an index normalized to $100=2000$.

$$
\mathrm{GDEM}_{\mathrm{t}}=\bar{\chi}_{i} \Sigma_{\mathrm{i}} \Delta \mathrm{m}_{\mathrm{it}}
$$

$\bar{\chi}_{i}=$ average $2000-03$ share of German goods export to country $i$. More precisely: $\bar{\chi}_{i}=\frac{\bar{x}_{i}}{\bar{x}_{G}}$ where $x_{i}$ are Germany's exports to country $i$ and $x_{G}$ are

Germany's total exports. The ratio is averaged over 2000-03.

$$
\Delta \mathrm{m}_{\mathrm{it}}=\text { annual growth rate of real goods imports in country } i
$$

Source: IMF World Economic Outlook database

Ginv (investment activity of German trading partners)

Export share weighted growth rates of real investment activity in Germany's trading partner countries.

$$
\begin{aligned}
& \mathrm{GINV}_{\mathrm{t}}=\bar{\chi}_{i} \Sigma_{\mathrm{i}} \varepsilon_{\mathrm{it}} i n v_{\mathrm{it}} \\
& \varepsilon_{\mathrm{it}}=\text { national currency/\$US exchange rate } \\
& i n v_{\mathrm{it}}=\text { real volume of investment activity }
\end{aligned}
$$

Source: IMF World Economic Outlook database

DomVA (domestic value added in industry)

Domestic value added as percent of total output of industrial sector.

Source: German Statistical Office GENESIS database and own calculations 


\section{APPENDIX B. ECONOMETRIC ANALYSIS}

\section{ADF Testing for Variables}

Table 2.B contains the results from the ADF tests. The top half of the table is testing whether the series in levels are stationary $\mathrm{I}(0)$ and the bottom half of the table is testing whether the first difference of the series is stationary I(1). There are six columns in the table. The first column gives the variable. Columns two and three provide the t-statistic from the ADF test and the implied coefficient on the lagged level term. The last three columns help to explain the lag specification of the model; they are the t-statistic on the maximum significant lag of the differenced variable, the maximum lag length chosen for the test and the associated AIC value. The t-DY lag and AIC measures are used in evaluating the appropriate number of lags in the testing procedure which remove serial correlation in the residuals.

The null hypothesis in the each test is that there is a unit root or the series is I(1); this implies that the coefficient $\alpha_{1}$ is insignificant from zero. Because of the properties of non-stationary series, the distribution of the statistics is different. The critical values are found at the bottom of the table. Centered Seasonal dummies were used for the export series (xgr) and the value added series (ind_va). We cannot reject the null of a unit root in the level of the variables. The first differences of the demand series (gdemo) and the investment series (ginv) have ADF t-statistics which are right on the threshold at 5\% rejection for the null of rejecting the unit root hypothesis. If examine the results further we note that the implied value for the lagged term is numerically far from unity. Thus, we concluded that these two series are best characterized as $\mathrm{I}(1)$ and not $\mathrm{I}(2)$ processes.

\section{Lag Length Selection of VAR}

The statistical VAR system can be generally specified as:

$$
\begin{aligned}
& {\left[\begin{array}{c}
\text { Exports }_{t} \\
\text { REERu }_{t} \\
\text { Demand }_{t} \\
\text { Other }_{t}
\end{array}\right]=\Pi(L)\left[\begin{array}{c}
\text { Exports }_{t-1} \\
\text { REERu }_{t-1} \\
\text { Demand }_{t-1} \\
\text { Other }_{t-1}
\end{array}\right]+B\left[\begin{array}{c}
\text { constant } \\
\text { Cseasonals }_{t}
\end{array}\right]+\left[\begin{array}{c}
\varepsilon_{1, t} \\
\varepsilon_{2, t} \\
\varepsilon_{3, t} \\
\varepsilon_{4, t}
\end{array}\right]} \\
& \text { where } \Pi(L)=\Pi_{1} L+\Pi_{2} L^{2}+\Pi_{3} L^{3}+\ldots+\Pi_{p} L^{p}
\end{aligned}
$$

The series in our analysis are in levels and have been transformed into natural logarithms. Constant and centered seasonal terms are included in each equation, because we use seasonally unadjusted data for German exports. The error terms are assumed to be white noise and can be contemporaneously correlated. The expression $\Pi(L)$ is a lag polynomial operator indicating that $p$ lags of each price is used in the VAR. The individual $\Pi_{i}$ terms represent a 4x4 matrix of coefficients at the ith lag.

The maximum possible lag length considered was six. The first three columns show the number of observations, number of lags, and estimated parameters for each VAR respectively. The log likelihood is given in the fourth column. The last three columns contain the Bayesian Schwartz Criterion (BSC), the Hannan-Quinn Criterion (HQ), and the Akaike Information Criterion (AIC) respectively. 
These are used as alternative criterion in testing. They rely on information similar to the ChiSquared tests and are derived as follows:

$$
\begin{aligned}
B S C & =\log (\operatorname{Det} \hat{\Sigma})+2 * c * \log (T) T^{-1} \\
H C & =\log (\operatorname{Det} \hat{\Sigma})+2 * c * \log (\log (T)) * T^{-1} \\
A I C & =\log (\operatorname{Det} \hat{\Sigma})+2 * c * T^{-1}
\end{aligned}
$$

Intuitively, the log determinant of the estimated residual covariance matrix will decline as the number of regressors increases, just as in a single equation ordinary least squares regression. It is similar to the residual sum of squares or estimated variance. The second term on the right hand side acts as a penalty for including additional regressors (c) which are scaled by the inverse of the number of observations (T). It increases the statistic. Once these statistics are calculated for each lag length, the lag length chosen is the model with the minimum value for the statistics respectively. The three tests do not always agree on the same number of lags. The AIC is biased towards selecting more lags than is actually needed; this is not necessarily bad. However, in this case the test statistic is minimized at two lags for all three criteria.

Tables 3.A-D contain the test statistics from the lag length tests. The first column is the number of lags in the VAR. The Schwarz, Hannen-Quinn, and Akaike Information Criteria are presented in columns five, six, and seven respectively. Similar results for the lag length in Models A and B are found. Both the SC and the HQ suggest that three lags are sufficient while the AIC implies that five and four lags are appropriate respectively. Model C incorporating both the standard export demand model with the domestic investment driven model appears to need two lags with the SC, three lags with the HQ and five lags with the AIC. Model D, the standard export demand augmented with the regionalization of the production process has the same results as model A.

The F-test is a finite sample criteria used for testing the lag length. It takes a slightly different form in the system or multi-equation case.

$$
\frac{\operatorname{Det}\left(\hat{\Sigma}_{R}\right)-\operatorname{Det}\left(\hat{\Sigma}_{U}\right)}{\operatorname{Det}\left(\hat{\Sigma}_{U}\right)} \square F(R=n \times \operatorname{lags}, U=T \times n-n \times p-k)
$$

The test depends on the estimated variance-covariance matrix, $\hat{\Sigma}$, the number of lags, which have been restricted to zero times the number of equations, $\mathrm{n}$. The unrestricted model, $U$, is the number of observations times $\mathrm{n}$ minus the maximum number of lags $(p)$ times $n$ minus other variables $(k)$ in the model like deterministic components: constant, trends, and seasonal factors.

Table 4 A-D report the results of lag reduction tests. The test statistic is calculated for maintained models starting with the maximum number of lags, which is equal to five here, and then for one less number of lags for each time. This methodology is employed to remove potential errors due to path dependence in testing. For example, lag 3 may appear to not significantly affect the explanatory power of models with five lags, but it could affect a 
model with four lags. There are four columns in Table 4 with a heading for the maximum number of lags. Below each is the F-test with the p-value reported in brackets for reducing the number of lags to the number in the row. We find that the maximum number of lags is five, three, three, and five lags in Tables 4 A-D respectively. Further lags lead to a loss of explanatory power in the respective system.

\section{The Residual Diagnostics from the VAR Models}

Tables 5.A-D contain the residual diagnostic tests for the VAR by equation and the vector or system tests. While the VAR models residual properties may meet the white noise standard, the data generating process may have undergone changes. The Portmanteau test and vector tests aimed at detecting autocorrelation, deviation from normality, and heteroskedasticity did not detect significant departures from white noise residuals. The one exception is model $\mathrm{C}$ which exhibits some autocorrelation in the demand (gdemo) and investment series (ginv).

\section{Recursive Analysis for Model Constancy and Stability}

Model constancy and tests for structural breaks of the VAR system were conducted using recursive estimation techniques. The textbook approach to model constancy assumes that modeler knows the date of a possible structural break in the sample. He/she fits the model over the full sample and for the two "halves" of the sample. The full sample implicitly imposes the same model structure throughout and can be considered a restricted model. This is evaluated against the unrestricted model comprised of the two "halves" using an F-test. We take an agnostic view on the possibility and timing of structural breaks over the sample 1993-2005.

In particular, the shocks discussed earlier may have impacted the dynamic relationships among the variables. Structural changes to the German domestic economy could have occurred through unification and changes in labor markets. Similarly, on the international side, demand and supply factors from globalization, uneven growth, and European integration could have caused changes in the process. Any or all of these events could have contributed to instability or "structural" breaks in the data generating process for Germany's exports of goods.

We computed two types of recursive Chow tests. The first is the 1-step Chow test. This looks at the sequence of one period ahead prediction from the recursive estimation for period $\mathrm{s}$ to The N-down test or Break-Point Chow test computes the test statistic over the sample scaled by either the 5 percent or 1 percent critical value and can be interpreted as a forecast stability of test. The results of the 1-step ahead Chow tests and the Break-point Chow test cannot reject the null hypothesis of no structural break.

\section{The Cointegration Analysis of the Vector Autoregression Model}

In this section the Johansen procedure is applied to test for the presence of cointegration. Engle and Granger (1987) demonstrate the one-to-one correspondence between cointegration and error correction models (ECMs). Cointegrated variables imply an error correction representation for the econometric model and, conversely, models with valid ECMs impose cointegration. The VAR model in levels presented earlier can be linearly transformed into one in first differences which is interpreted as a VECM or vector error correction model. 


$$
\begin{aligned}
& {\left[\begin{array}{c}
\Delta \text { Exports }_{t} \\
\Delta \text { EER }_{t} \\
\Delta \text { Demand }_{t} \\
\text { } \text { Other }_{t}
\end{array}\right]=\Pi\left[\begin{array}{c}
\text { Exports }_{t-1} \\
\text { REERu }_{t-1} \\
\text { Demand }_{t-1} \\
\text { Other }_{t-1}
\end{array}\right]+\Gamma(L)\left[\begin{array}{c}
\Delta \text { Exports }_{t-1} \\
\Delta R E E R u_{t-1} \\
\Delta \text { Demand }_{t-1} \\
\Delta \text { Other }_{t-1}
\end{array}\right]+B\left[\begin{array}{c}
\text { constant }_{\text {Cseasonal }_{t}}
\end{array}\right]+\left[\begin{array}{c}
\varepsilon_{1, t} \\
\varepsilon_{2, t} \\
\varepsilon_{3, t} \\
\varepsilon_{4, t}
\end{array}\right]} \\
& \text { where } \Pi(L)=\Pi_{1} L+\Pi_{2} L^{2}+\Pi_{3} L^{3}+\ldots+\Pi_{p} L^{p} \\
& \varepsilon \square(0, \Omega), \quad \Gamma_{i}=-\sum_{j=i+1}^{p} \Pi_{j}, \quad \Pi=\sum_{i=1}^{p} \Pi_{i}-I
\end{aligned}
$$

The crux of the Johansen test is to examine the mathematical properties of the $\boldsymbol{\Pi}$ matrix which contains important information about the dynamic stability of the system. Intuitively, the $\boldsymbol{\Pi}$ matrix contains the expression relating the levels of the endogenous variables in the system.

Evaluating the number of linearly independent equations in $\boldsymbol{\Pi}$ is done by testing for the number of non-zero characteristic roots, or eigenvalues, of the $\Pi$ matrix, which equals the number of linearly independent rows. ${ }^{13}$ The matrix can be rewritten as the product of two full column vectors, $\Pi=\alpha \beta^{\prime}$.

The matrix $\beta$, is referred to as the cointegrating vector and $\alpha$ as the weighting elements for the rth cointegrating relation in each equation of the VAR. The vector $\beta^{\prime} Y_{t-1}$ is normalized on the variable(s) of interest in the cointegrating relation(s0 and interpreted as the deviation(s) from the "long-run" equilibrium condition. In this context, the column $\alpha$ represents the speed of adjustment coefficients from the "long-run" or equilibrium deviation in each equation. If there is a single cointegrating relation and the coefficient is zero in a particular equation, that variable is considered to be weakly exogenous and the VAR can be conditioned on that variable. Weak exogeneity implies that the beta terms or long-run equilibrium relations do not provide explanatory power in a particular equation. If that is true, then valid inference can be conducted by dropping that equation from the system and estimating a conditional model.

Using the model specifications A-D the unrestricted VAR was estimated using ordinary least squares. The results of the Johansen cointegration test are presented in Table 6.A-D. Each table is partitioned into 5 parts. The first provides the tests for cointegration and the reduced rank standardized coefficients. The next two parts show individual hypotheses tests on the $\beta$ and $\alpha$ vectors respectively. The next part reports the final test for the vectors jointly. Fifth the final reduced form rank relations are formed.

\footnotetext{
${ }^{13}$ The number of linearly independent rows in a matrix is called the rank.
} 
The eigenvalues of the $\Pi$ matrix are sorted from largest to smallest. The tests are conducted sequentially, first examining the possibility of no cointegrating relation against the alternative that there is one cointegrating relations, and then the null of one cointegrating relation against the possibility of two cointegrating relations, e.g. essentially, these are tests of whether the eigenvalue(s) is (are) significantly different from zero.

We found that there appears to be a cointegrating relation in Models A, C, and D. There does not appear to be one for Model B. There is no further discussion of this model. We rejected the null of no cointegration or rank zero for the three models, but could not do so in the one. The test for no cointegration $(\mathrm{r}=0)$ in the standard export demand model is rejected at 0.04 with the Trace test (30.54), but not the Max(eigenvalue) test (16.07). The same tests in 6.C are rejected at 0.01 and 0.04 respectively. In Table 6.D including the value added in industry to the model for regionalization of the production hypothesis, the Trace test is rejected at 0.01 and 0.02 with the Max(eigenvalue) test There was no evidence suggesting that there was a second cointegration relation among the variables in the four models. We test and attempt to interpret the relations as "equilibrium models" of German goods exports.

The first standardized eigenvector or $\beta$ vector is normalized on German exports. Our hypothesis is that the "long-run" or equilibrium relation explains export demand. The second part of each table reports the estimates for the two vectors and their associated standard errors in four columns under the assumption of single cointegrating relation. The $\beta$ coefficients for the real effective exchange rate, LREER $u$, foreign demand, and LGdem, 0.17 and -1.06 respectively. The signs are reported as if the sum of the entire vector equals zero, thus the opposite signs. One can interpret these coefficients as suggesting German exporters have inelastic even in the long-run and that the income elasticity of German exports is close to unity. These tests are conducted in the third part of Table 6.A.

Next, we conduct hypothesis tests on the $\alpha$ vector. The third column of the second part shows the speed of adjustment coefficients, $\alpha$. If the cointegrating relation we have specified is appropriate (and stationary), then at its own coefficient must be negative. In this case, the estimate is -0.52 and significant. We can test if the other $\alpha$ terms are significant, that is whether the equations for those variables are influenced by the cointegrating relation. First, we check if the cointegrating relation is as identified by examining its $\alpha$ or speed of adjustment coefficient. It must be negative for the relation to be consistent with a stationary process. The standardized $\alpha$ coefficients and the associated tests for weak exogeneity are found in part four of the table below the hypotheses for $\beta$ tests.

We test whether the $\beta$ coefficients help to explain exports and are interpretable in an economic context. Chi-square tests report the null hypothesis over whether there is zero explanatory power individually and jointly. The $\mathrm{p}$-value for testing the real exchange rate elasticity is zero cannot be rejected individually. Foreign demand is clearly significant. The joint test suggests that both variables are significant. Further, we cannot reject the null hypothesis, that income demand elasticity is unity at 0.1 significance. The speed of adjustment or $\alpha$ coefficients are tested individually for significance. We find that only the export series, $L x g r$, is significant and only at 0.07 . The joint hypothesis that both $L R E E R u$ and $L G d e m$ are zero cannot be rejected with a p-value of 0.27 . 
At the bottom of the table we report the joint tests for the $\beta$ and $\alpha$ coefficients. We find that the null of a unit income elasticity and weak exogeneity for the exchange rate and foreign demand cannot be rejected with a p-value of 0.28 . The final standard export demand relation for model A included these hypotheses is given by

$$
\begin{aligned}
& \text { Exports }_{t}=-0.42 \text { Real Effective Exchange Rate }{ }_{t}+1 \text { Global Export Demand }_{t} \\
& \text { Speed of Adjustment }=\alpha=-0.63
\end{aligned}
$$

The restriction of unit global demand elasticity could not be rejected. We found that global demand and the exchange rate could be treated as weakly exogenous. The speed of adjustment coefficient suggests that 85 percent of "disequilibrium" is corrected in four quarters.

Model $\mathrm{C}$ augments the standard export demand model by including domestic investment of Germany's export partners. The Johansen tests for cointegration suggest that there is the possibility of more than one cointegrating relation with the addition of the new variable. It may be due to common trends as well as common stochastic trends. The investment and demand series may be cointegrated in a long-run output investment relation when examining the data across all trading partners. We attempted to find a second cointegrating relation, but could not find a stable or meaningful relation. Thus, we proceeded with the idea of a single relation. ${ }^{14}$ The speed of adjustment coefficient in the alpha vector for exports is negative, but insignificant. The other coefficients are difficult to interpret. In particular, the negative sign on the real exchange rate measure may be puzzling.

We continue testing of the beta and alpha vectors in an attempt to uncover a possible reasonable model of the export demand relation through hypothesis testing. The individual tests for LREERu, LGdem, and LGinv reveal possible marginal significance for the first and significant values for the latter two series. A joint test for all three variables is significant at 0.02 . The equal but opposite sign or differential hypothesis could not be rejected; the test statistic is 1.32 with a p-value of 0.25 . The weak exogeneity tests in the fourth part of the table find that the speed of adjustment coefficient for exports, Lxgr, is not significant.

\footnotetext{
${ }^{14}$ This puzzle of the output investment ratio is borne out in the coefficients in the second part of Table 6.C. When we initially specified this model our hypothesis was that LGdem and LGinv would both have the same sign. However, they have opposite signs and have approximately the same magnitudes. This is consistent with the idea of a stable share of investment to GDP overtime and across trading partners. There are three reasons for this puzzle. First, the result becomes clearer when we disaggregate this ratio by different regions. Increases in export demand from other European countries are negatively correlated with investment activity, and that investment growth in the US is not correlated with export demand from the US. Since these two regions have a large weight in the aggregate index, they may account for the opposite signs. Second, further analysis highlights another potential problem with the investment measure. Implicitly the investment index assumes the fraction of capital goods imported per investment unit is constant across countries. This assumption is too restrictive and unlikely to hold. In particular, the import demand for capital goods from fast growing emerging markets may have been underestimated. The net effect of the countervailing influences cannot be assessed with the current data. The exchange rate elasticity is negative and perhaps significant.
} 
The final reduced form specification for export model $\mathrm{C}$ is given by:

$$
\begin{aligned}
& \text { Exports }_{t}=-0.27 \text { Real Effective Exchange Rate } \\
& \text { Speed of Adjustment }=\alpha=2.36\left(\text { Global Export Demand }_{t} / \text { Global Investment }_{t}\right) \\
& \text { Sp }=-0.33
\end{aligned}
$$

The exchange rate elasticity -0.27 significant at the 5 percent level. The speed of adjustment coefficient suggests that 90 percent of "disequilibrium" is corrected in four quarters. However, it is over marginal significance. Thus, we conclude that while there may be statistical evidence in favor of a cointegrating relation, it may not be appropriate to interpret it as an export demand relation. As a result we omitted the investment driven export demand specification or model. The puzzle(s) remains, but could be addressed through regional analysis of exports (e.g. Stahn 2006).

The final export model augments the standard export model by the regionalization of the production processes hypothesis (model D). The regionalization hypothesis was approximated by the share of domestic value added in industry (Dom_VA) which declined throughout the sample period. The Johansen Trace test and Max(eigenvalue) test suggest that there is evidence of a single cointegrating relation. The test statistics are 58.2 and 30.1 with associated p-values of 0.01 and 0.2 respectively.

When the value added term is included in the regionalization model, the exchange rate term is about the same as in Models $\mathrm{A}$ and $\mathrm{C}$ and the income or trading partner demand elasticity is less than unity. The value added term has the correct sign and is significant. The alpha term for exports is negative and very significant. In addition, the exchange rate and the value added variables may not be weakly exogenous. The exchange rate, trade partners' demand and value added are individually and jointly significant in the beta vector. We performed individual and joint tests for imposing a unit income or demand elasticity and it was rejected, but this was not the case when including tests for weak exogeneity.

The tests for weak exogeneity support that the speed of adjustment for Lxgr is different from zero, $L G d e m$ is not different from zero and that the exchange rate and value added variables are weakly exogenous at 0.10 , but not 0.05 . When we impose the restriction of a unit income elasticity and the joint hypothesis of weak exogeneity the test statistic is 6.99 with a p-value of 0.13 . The final cointegrating relationship is given by

$$
\begin{aligned}
& \text { Exports }_{t}=-0.19 \text { Real Effective Exchange Rate }{ }_{t}+0.77 \text { Global Export Demand }_{t}-4.0 \text { Value Added }_{t} \\
& \text { Speed of Adjustment }=\alpha=-0.37
\end{aligned}
$$

The exchange rate elasticity is 0.19 and indistinguishable from the standard export demand model. The test that the global demand elasticity was unity could not be rejected. Domestic value added has a negative sign meaning that the decline in domestic value added improved export growth. The speed of adjustment in this model or return from "disequilibrium" takes about 4 quarters. 
Figure 1. Germany GDP growth 1980-2005

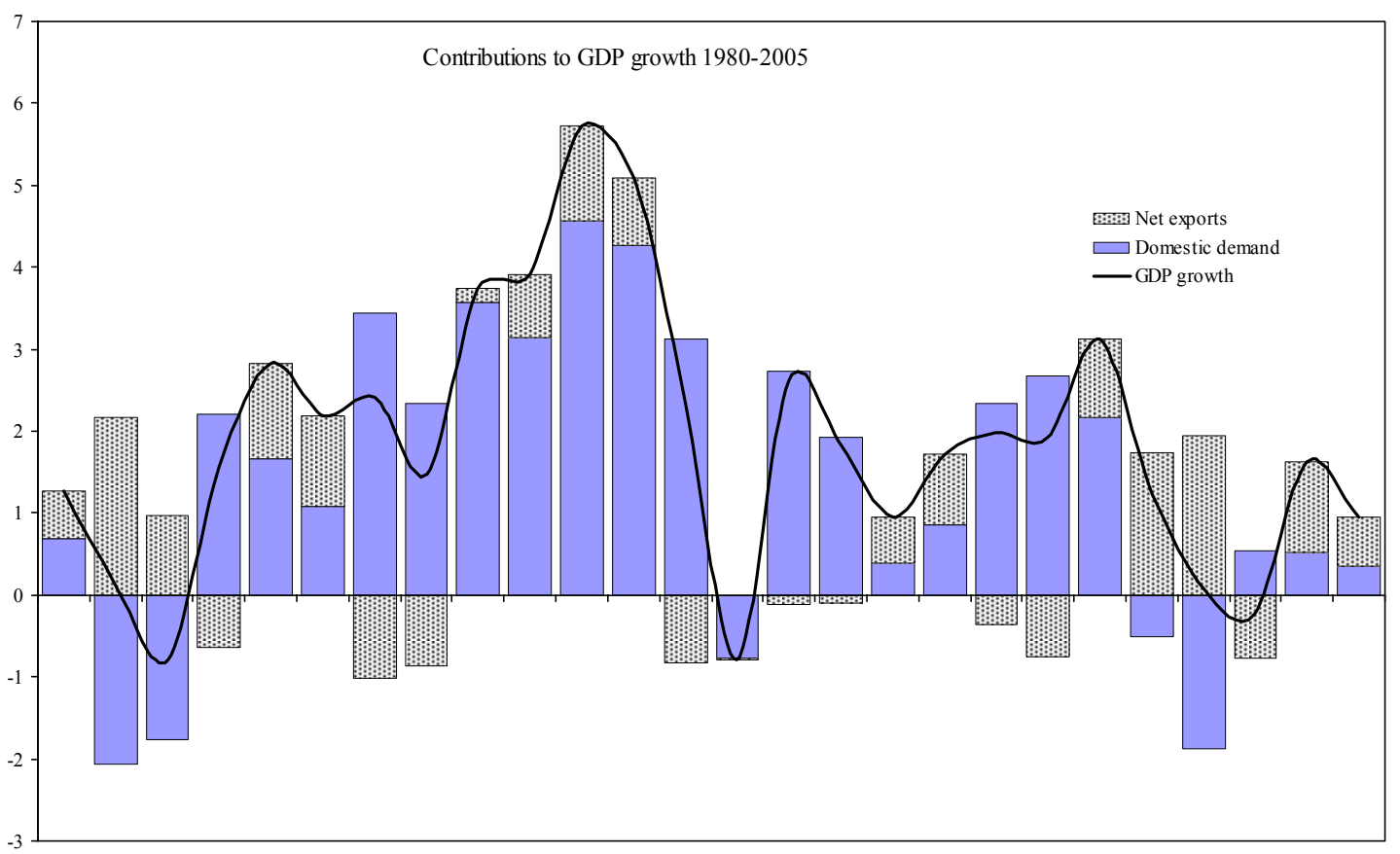

$\begin{array}{llllllllllllllllllllllllll}1980 & 1981 & 1982 & 1983 & 1984 & 1985 & 1986 & 1987 & 1988 & 1989 & 1990 & 1991 & 1992 & 1993 & 1994 & 1995 & 1996 & 1997 & 1998 & 1999 & 2000 & 2001 & 2002 & 2003 & 2004 & 2005\end{array}$ 
Figure 2. Germany: Export Market Shares Among Industrial Countries and the Euro Area 1990-2005

Export Market Share Index

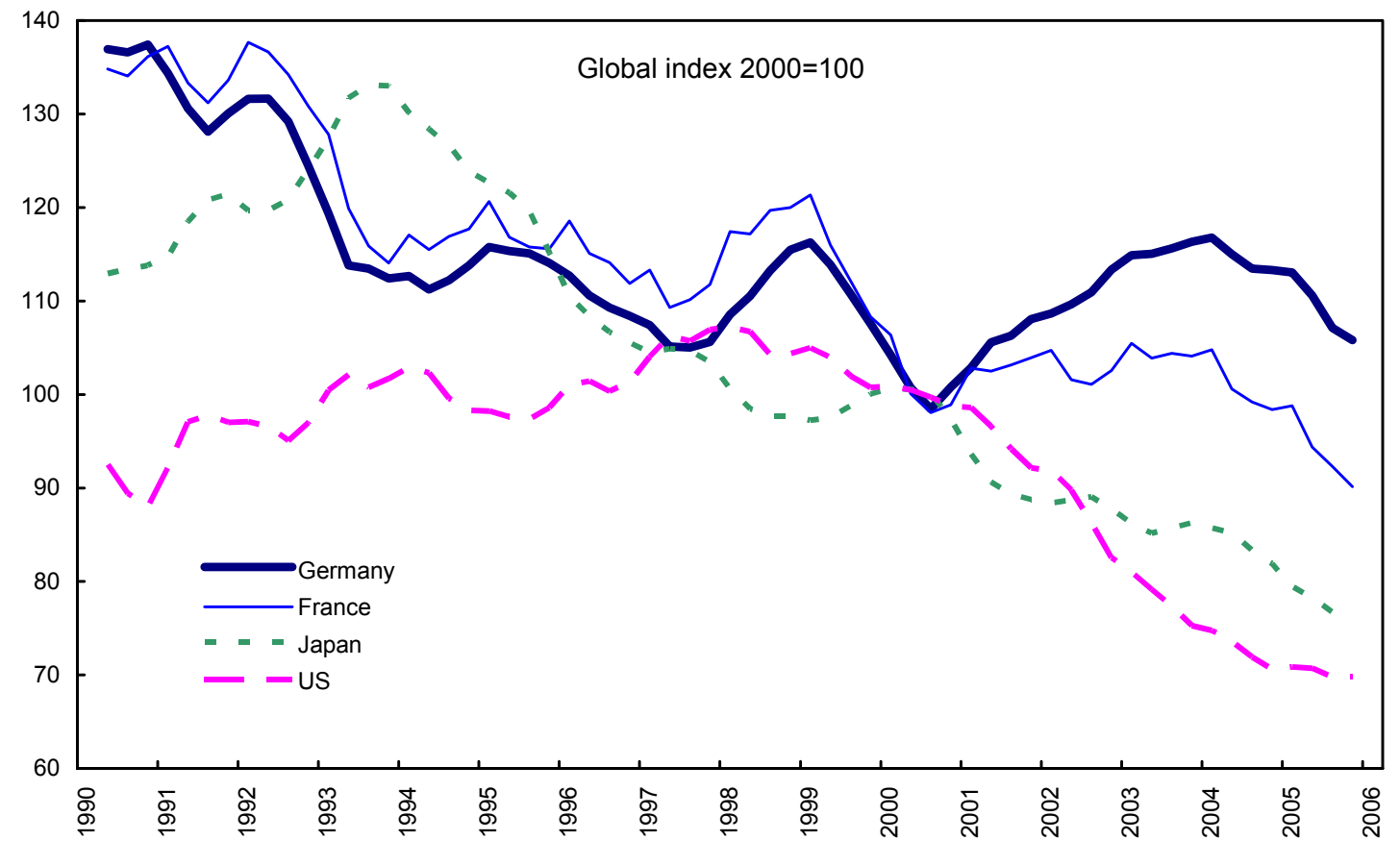

Export Market Share in Percent
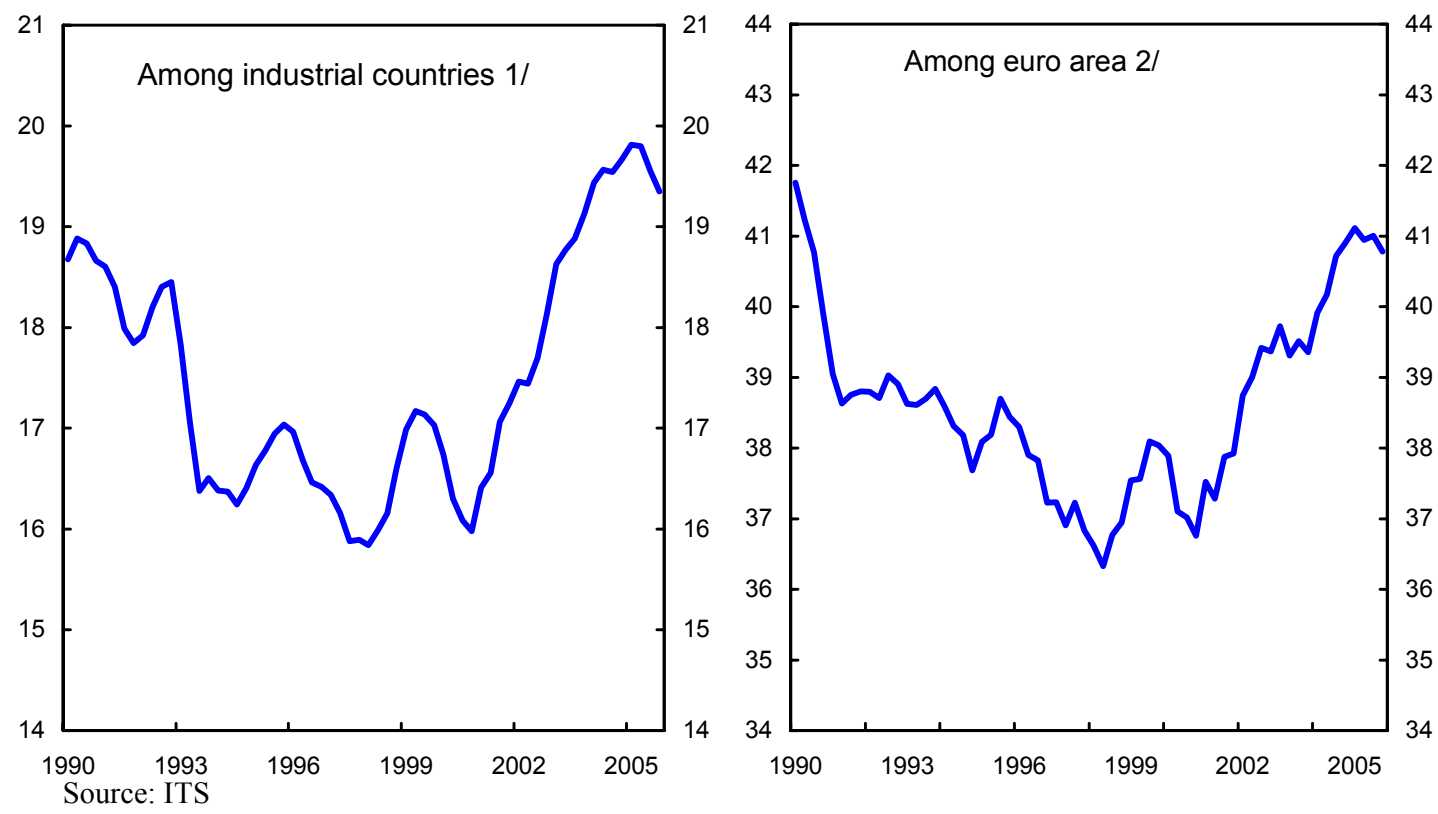

1/ Share of German imports in total imports of industrial countries from other industrial countries.

2/ Share of German imports in total imports of euro area from other euro area countries. 
Figure 3. Real Effective Exchange Rate at Unit Labor Costs Germany and Euro Area

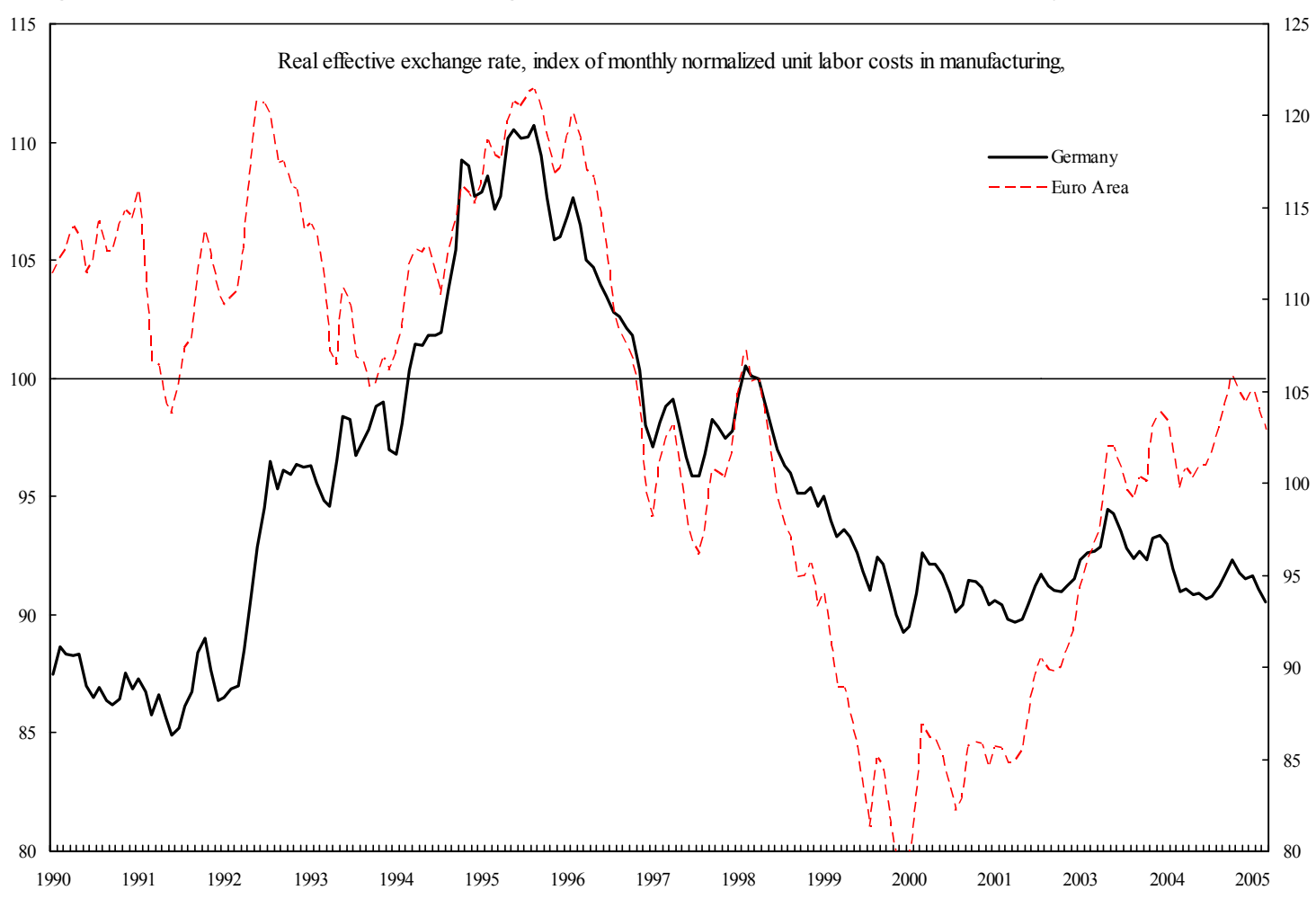


Figure 4. World Volume Growth and Germany's Demand Growth

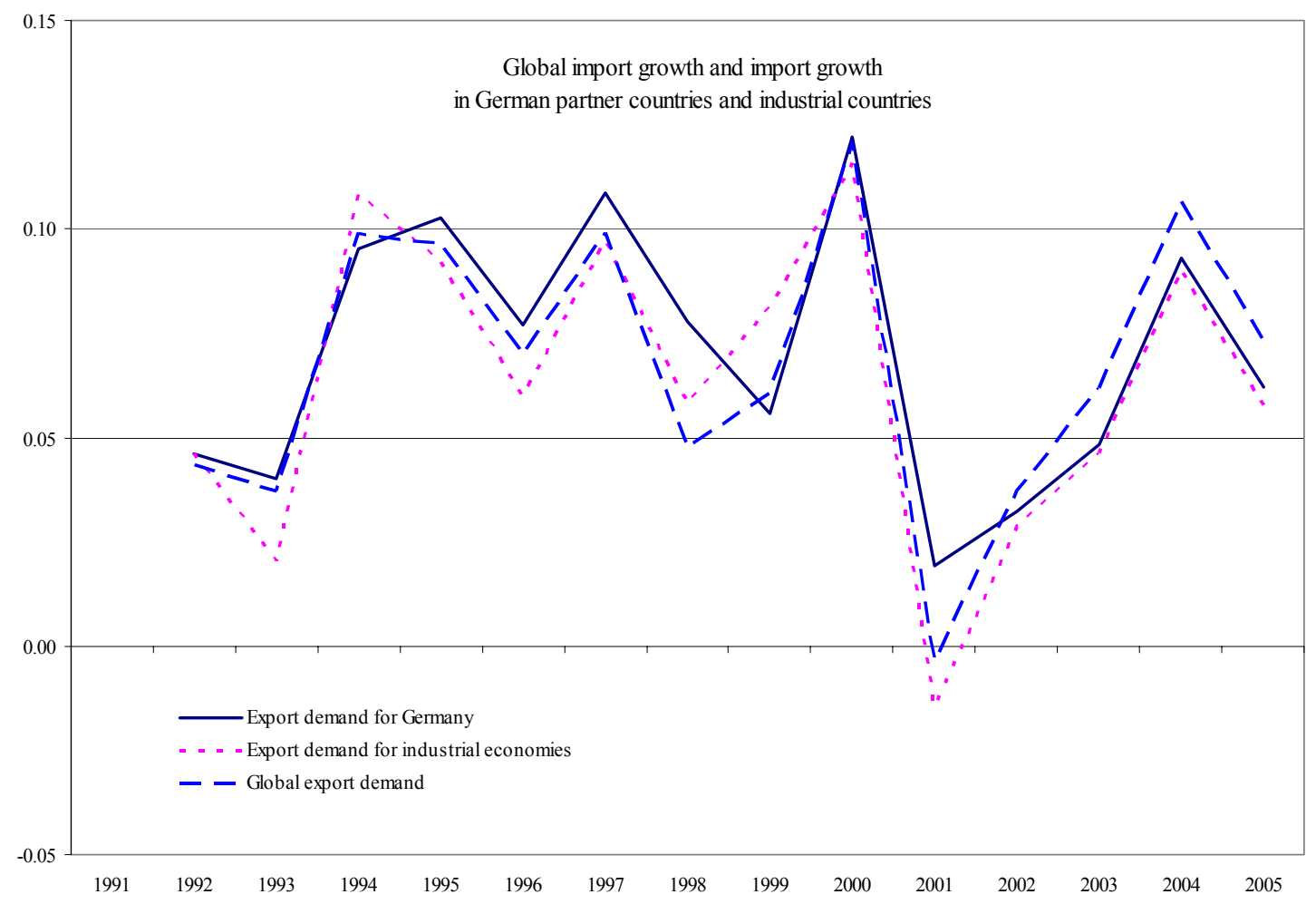

Source: WEO database. 
Figure 5. Global Investment Demand

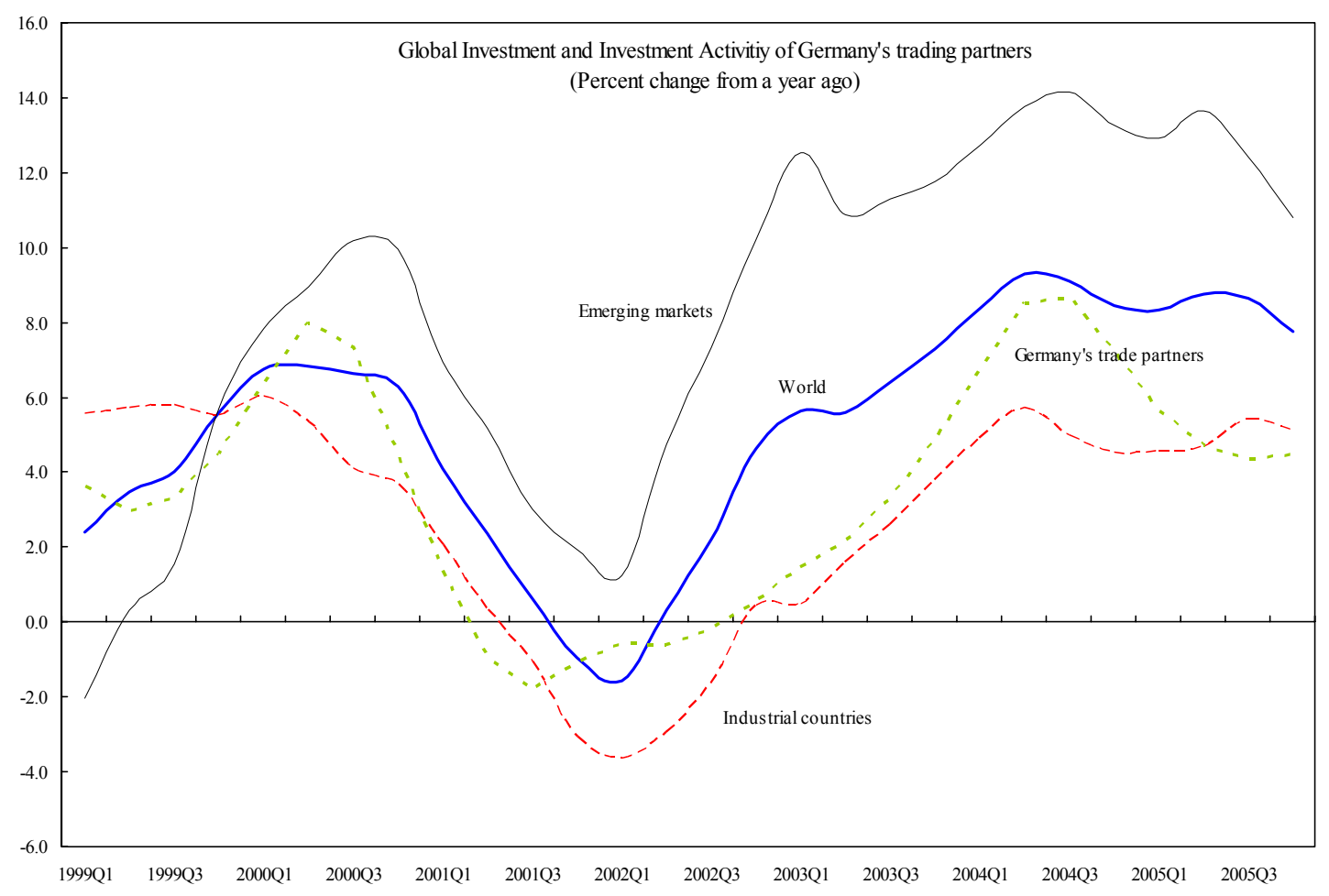

Figure 6. Development of Export Shares by Types of Export Goods

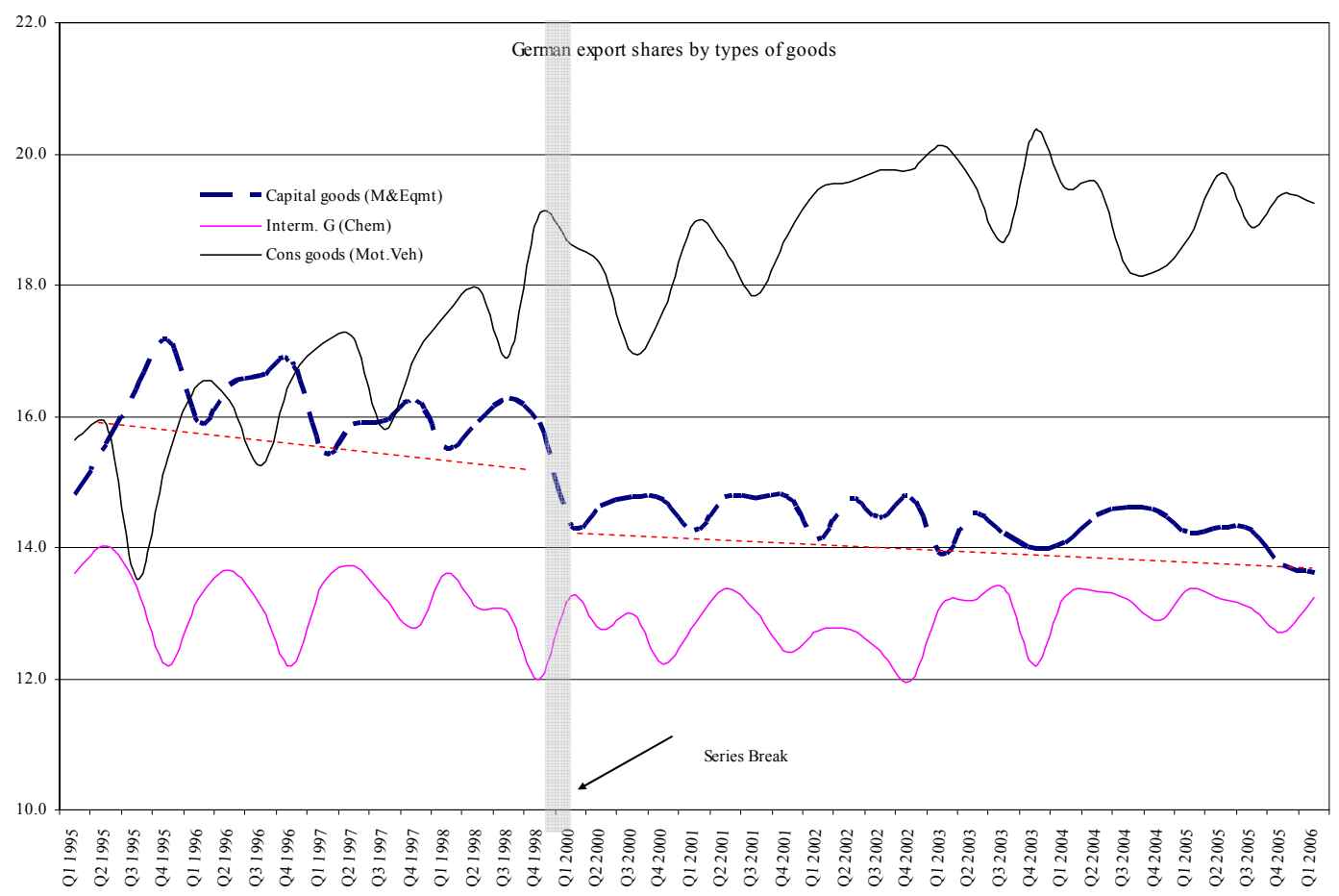


Figure 7. Composition of Industry Sector Output

Domestic value added and imported inputs of the export sector 1995-2005

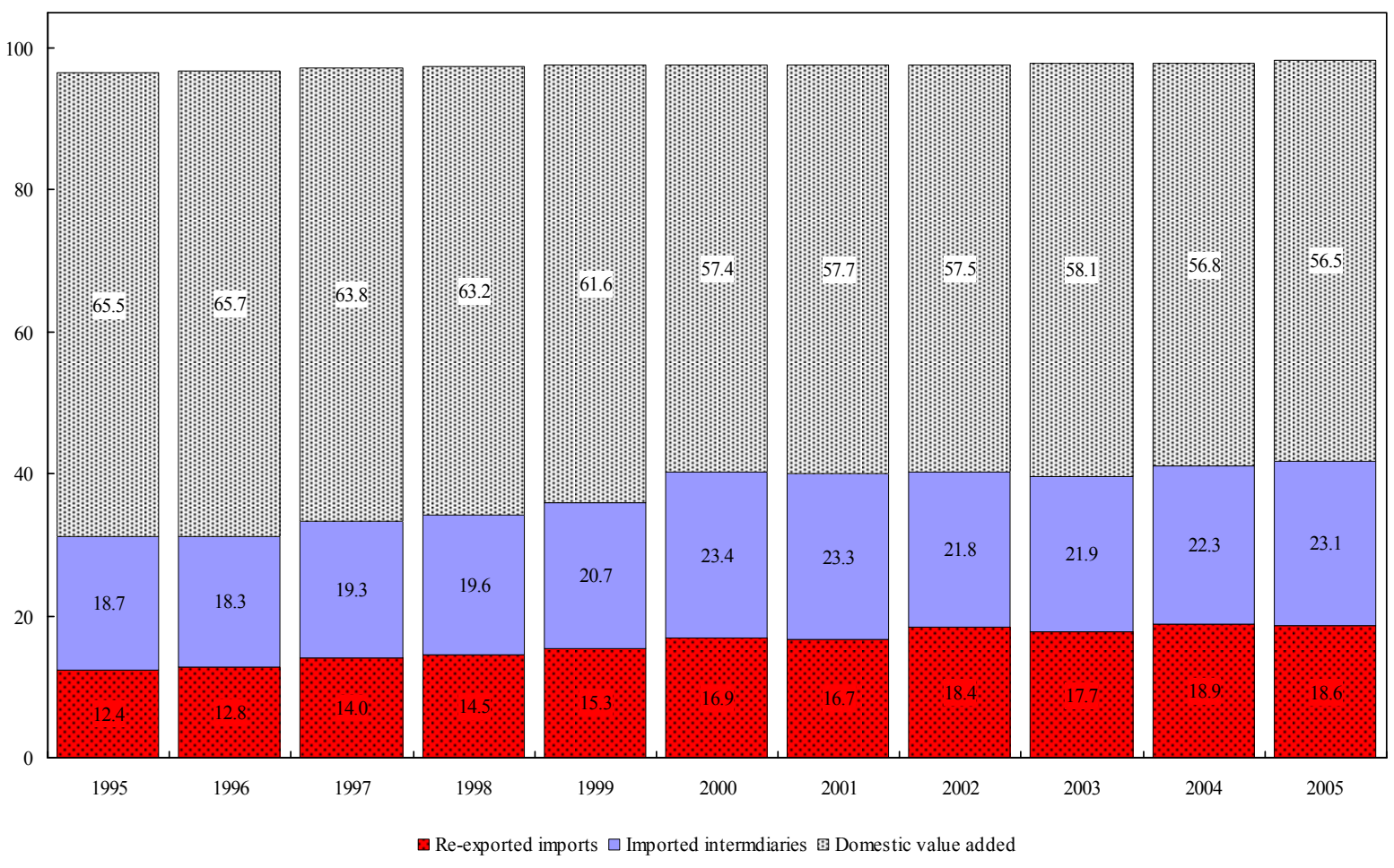

Figure 8. Wage Costs for German Enterprises from Outsourcing and Off-Shoring

Unit Labor Cost Relative to Germany
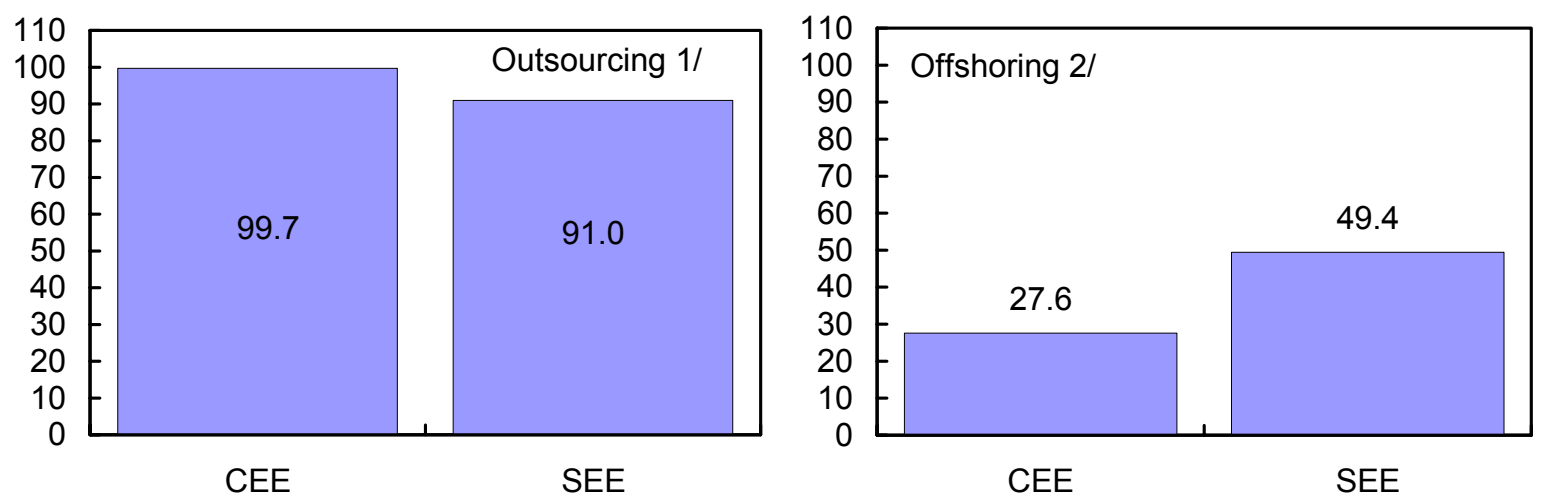

jource: Marin D. (2006) "A New International Division of Labor in Europe: Outsourcing and Offshoring to Eastern Europe" Journal of the European Economic Association, forthcoming.

/ Purchasing intermediate inputs from other providers in Central and Eastern Europe (CEE) and Southeastern Europe (SEE).

!/ Moving production capacity to CEE and SEE countries and thus increasing productivity closer to parent firm level. 
Figure 9. Time Series Plot of Main Variable (log levels except for ind_va) 1990-2005
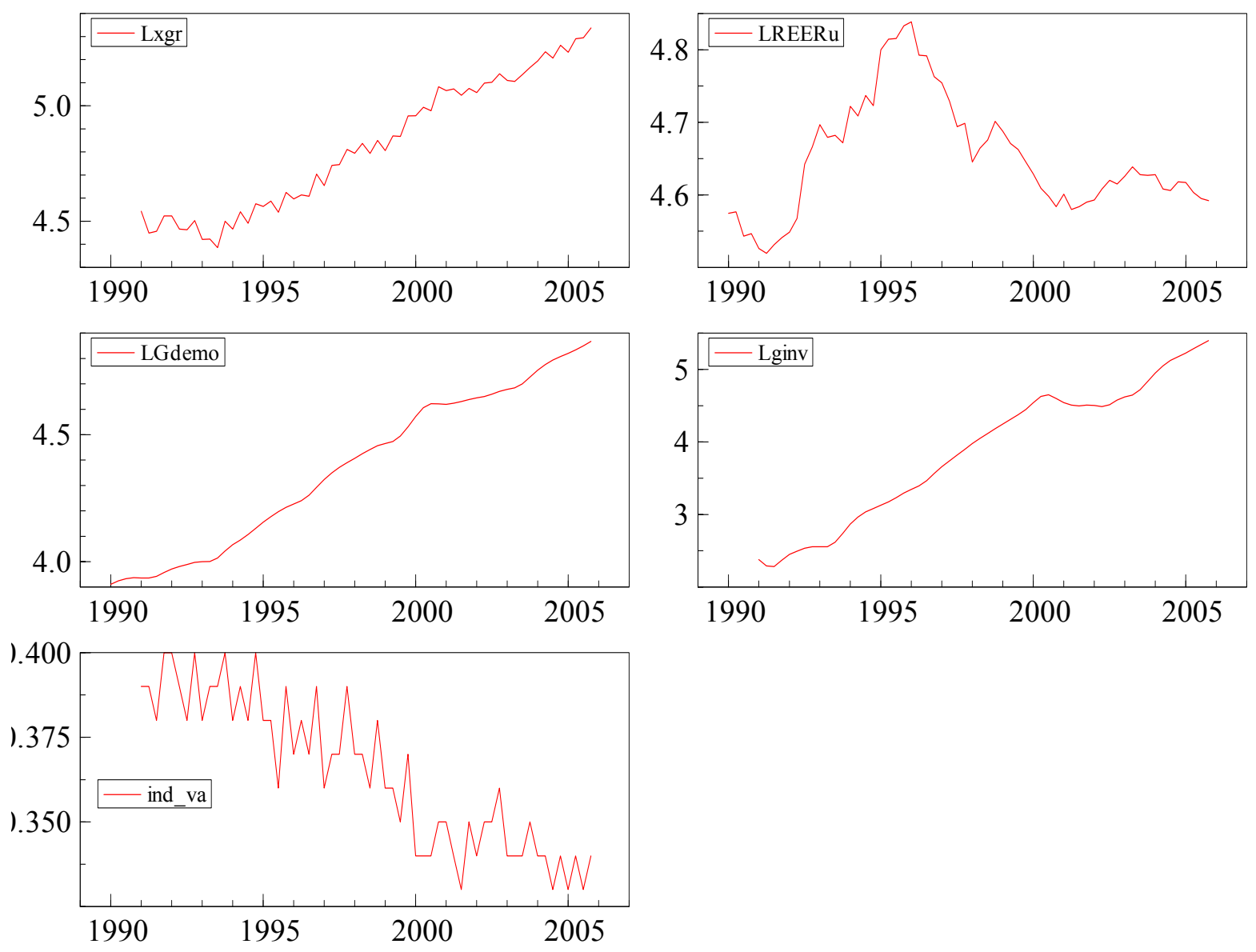
Figure 10.A Residual Diagnostics Standard Export Demand Model
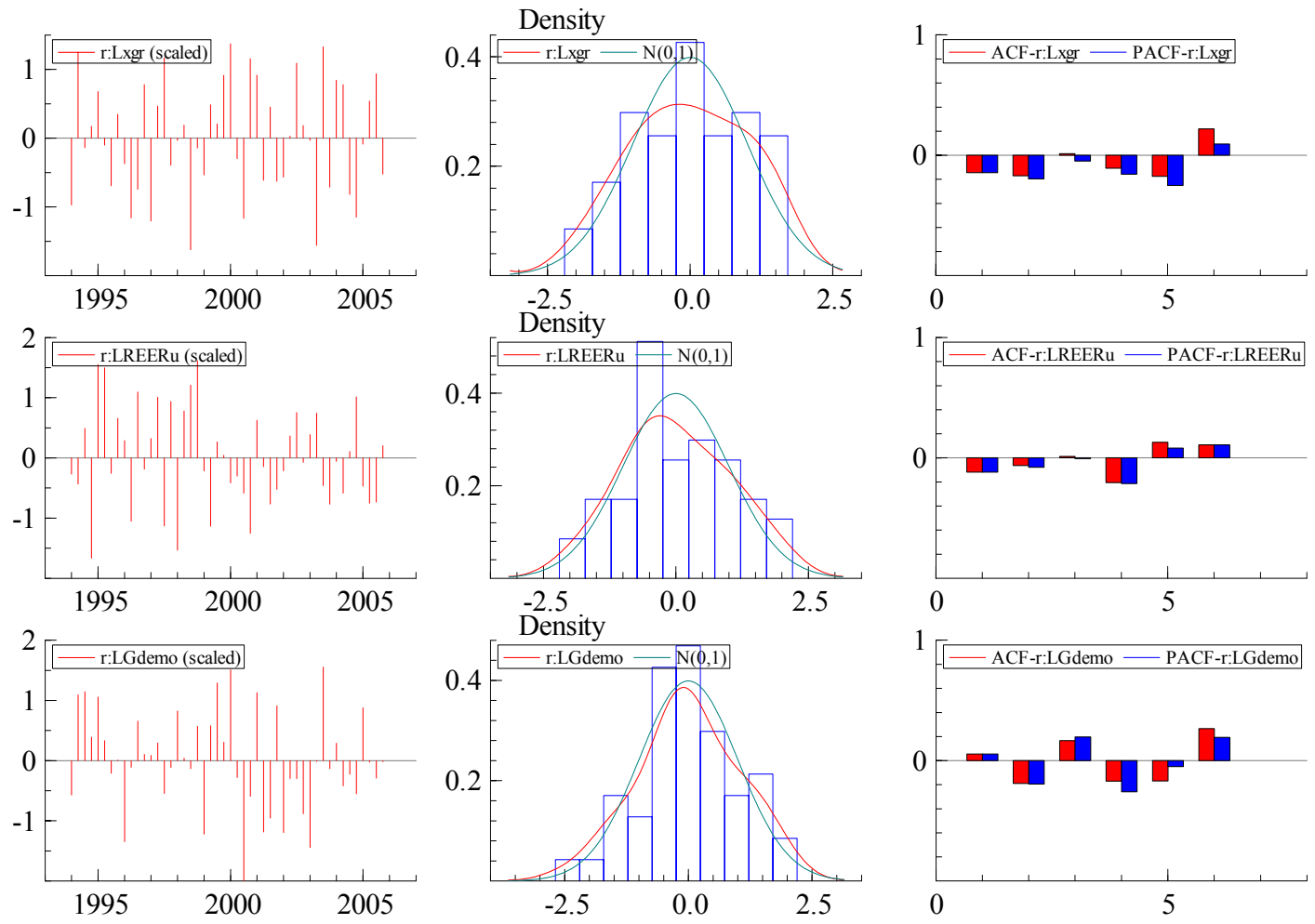

Figure 10.B Residual Diagnostics Export Demand Model Driven by Domestic Investment and Foreign Capital Goods
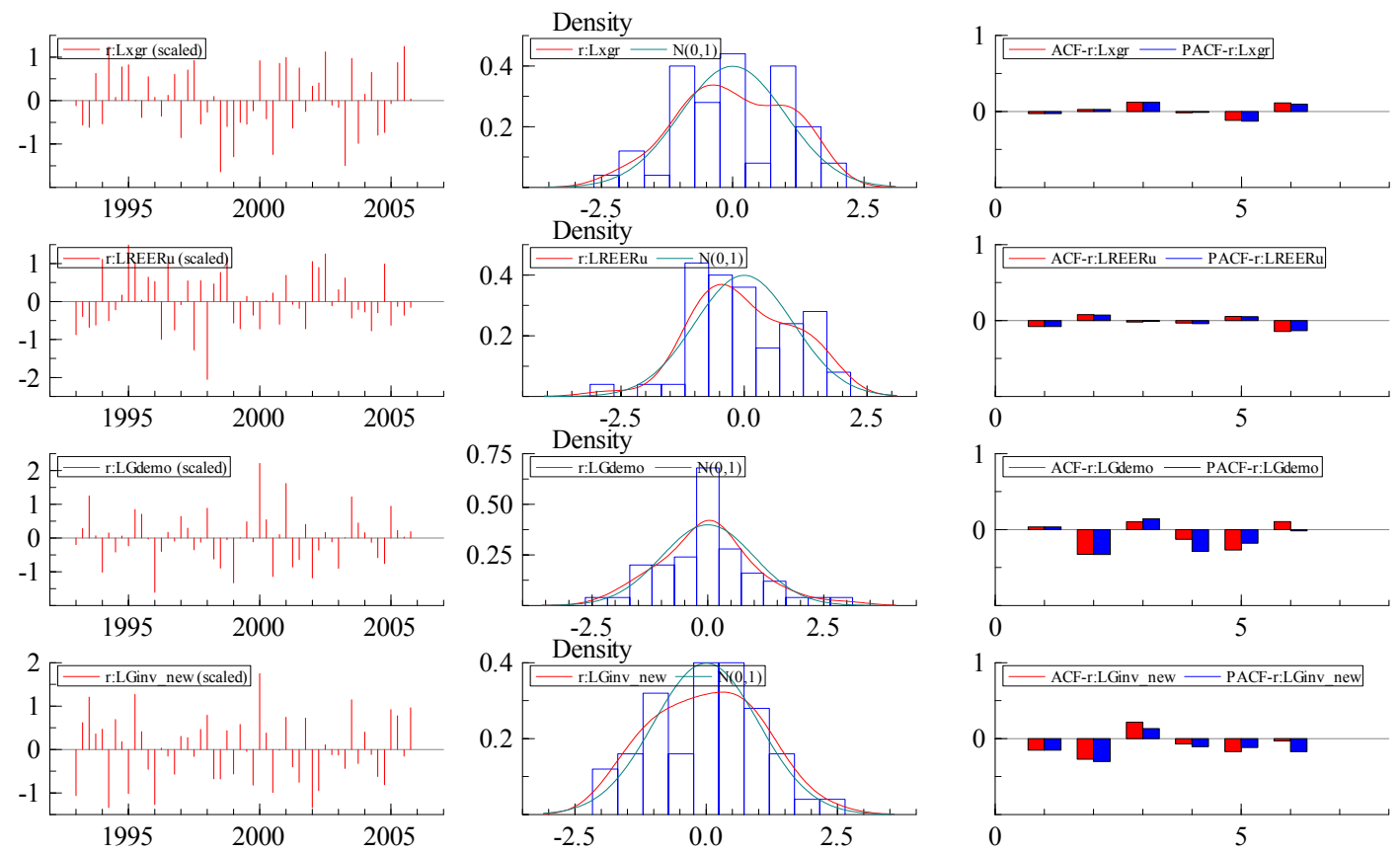
Figure 10.C Residual Diagnostics: Combination Standard Export Demand Model and Domestic Investment Driven Model for Foreign Capital Goods Model
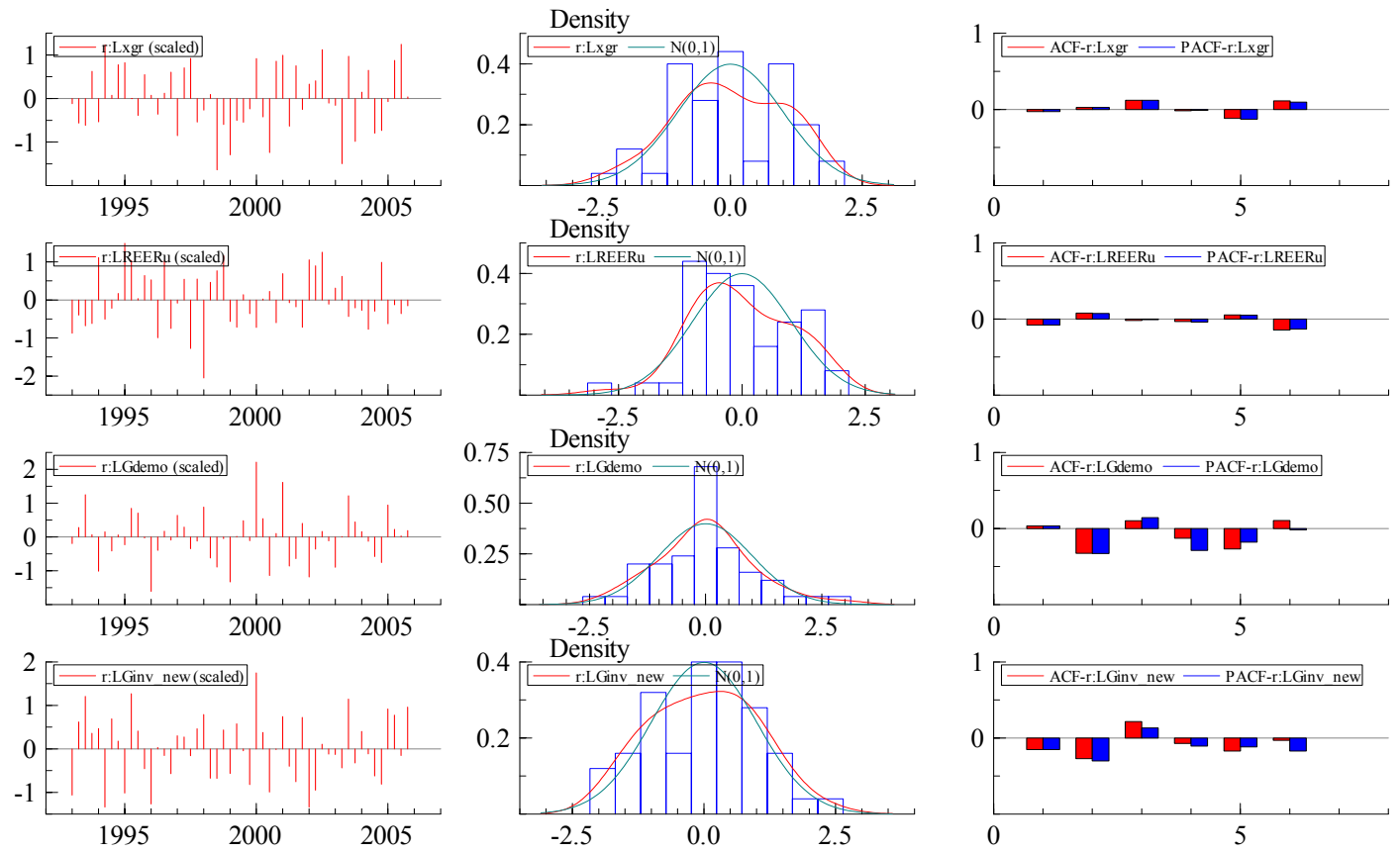

Figure 10.D Residual Diagnostics: Export Demand Model Driven by Regionalization of Production Processes
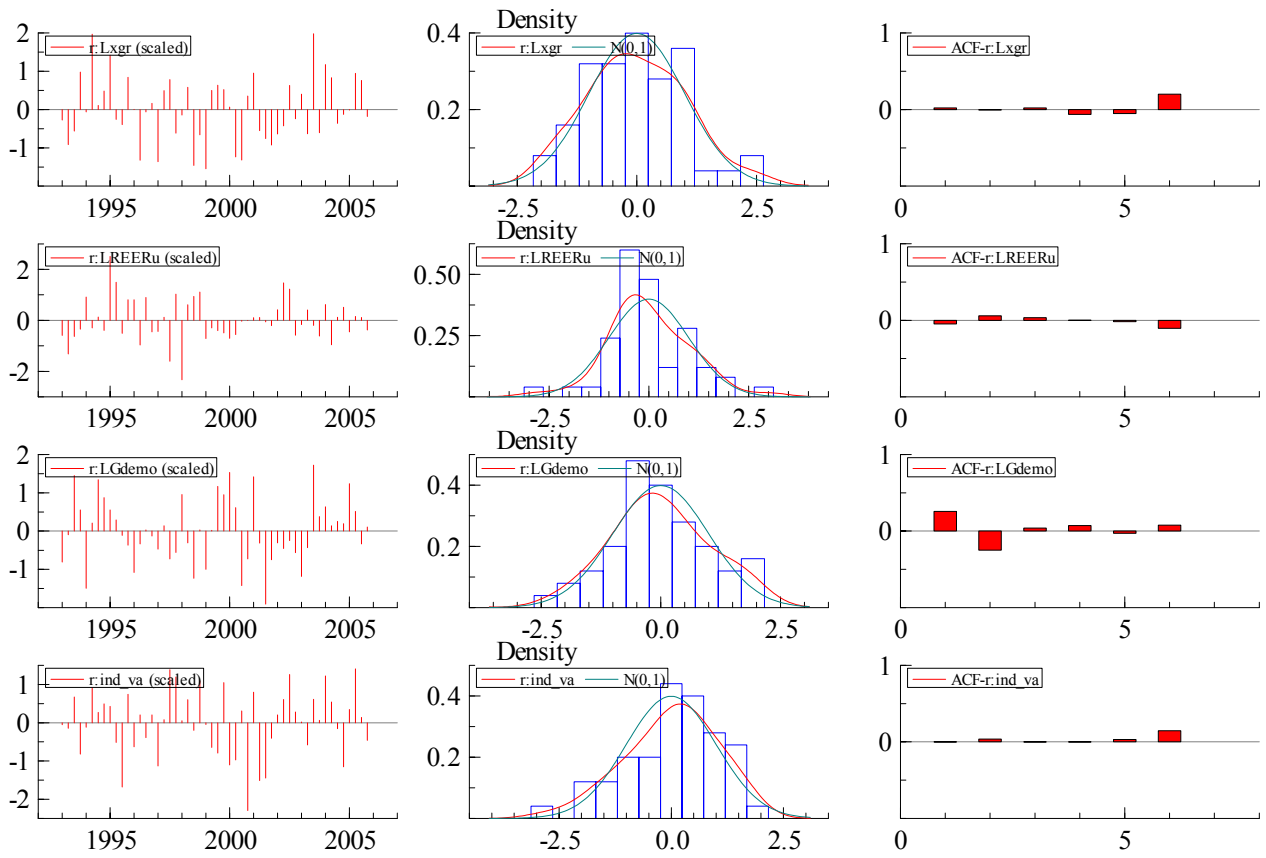
Figure 11.A Recursive Stability Analysis: Standard Export Demand Model Model 15 Lags Recur
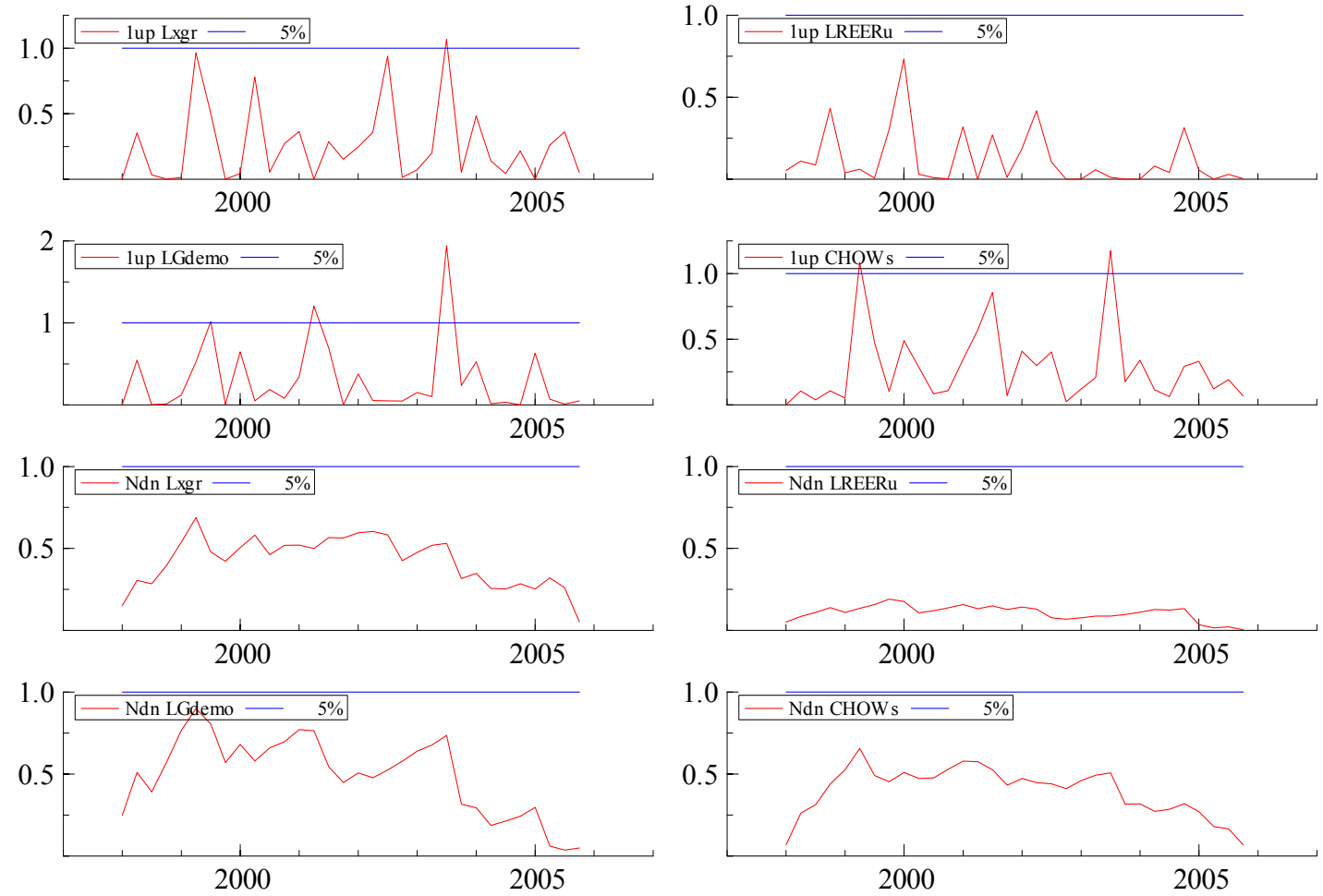

Figure 11.B Recursive Stability Analysis: Export Demand Model Driven by Domestic Investment and Foreign Capital Goods

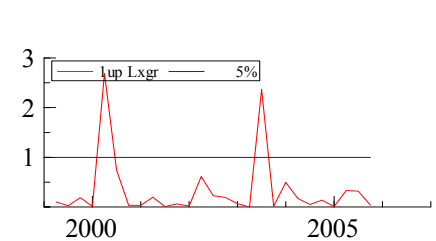

Model 4 - 5 Lags Recursive
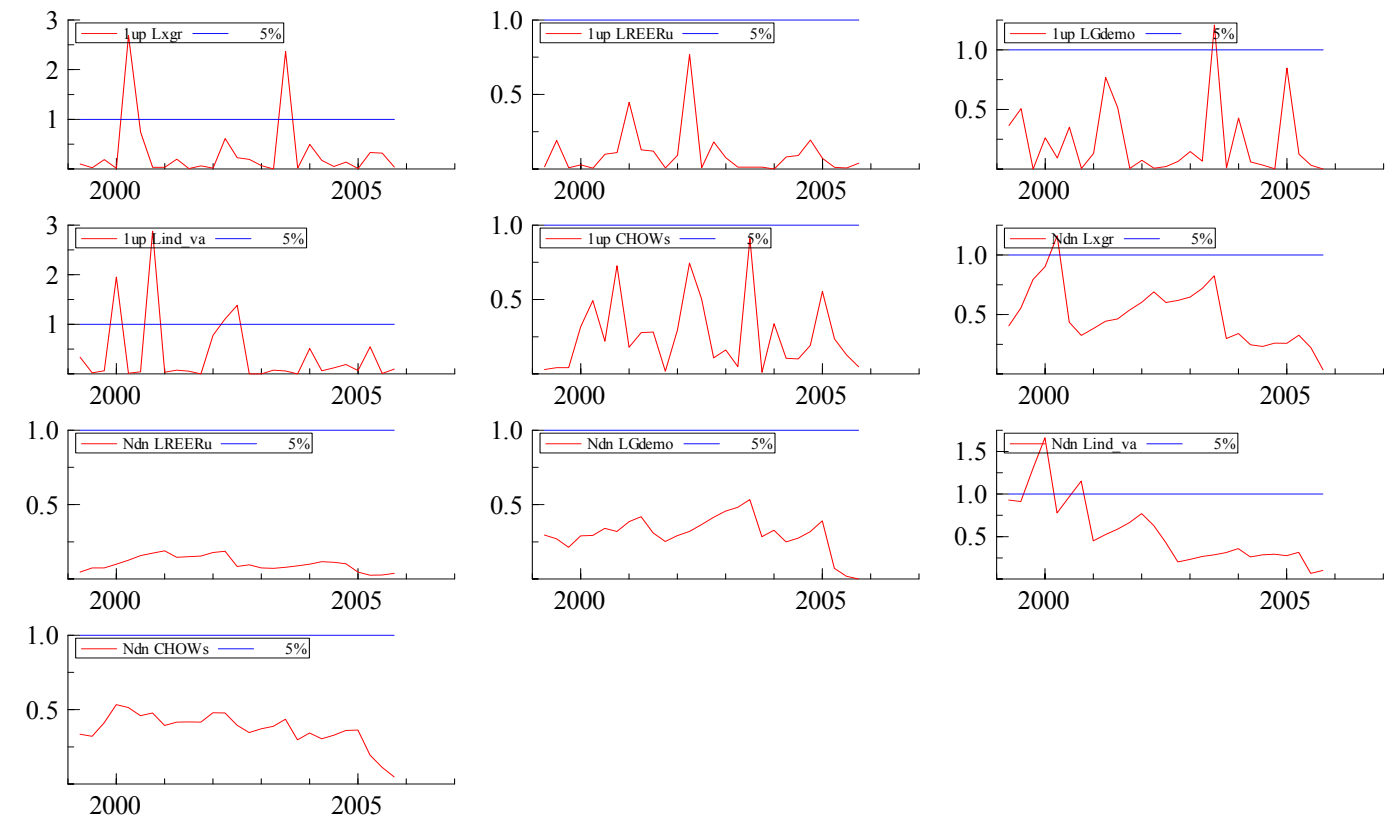
Figure 11.C Recursive Stability Analysis: Combination Standard Export Demand Model and Domestic Investment Driven Model for Foreign Capital Goods Model
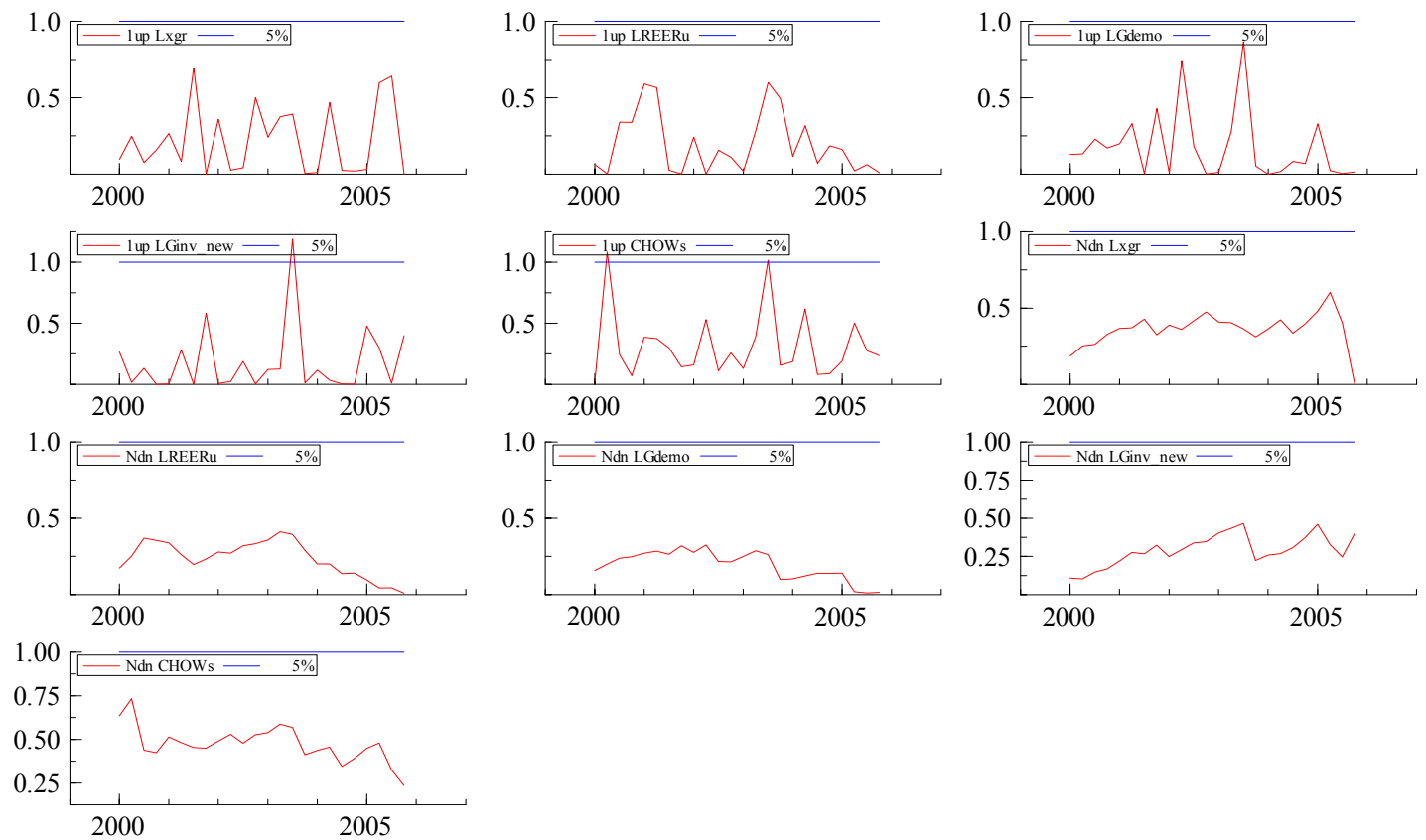

Figure 11.D Recursive Stability Analysis Export Demand Model Driven by Regionalization of Production Processes
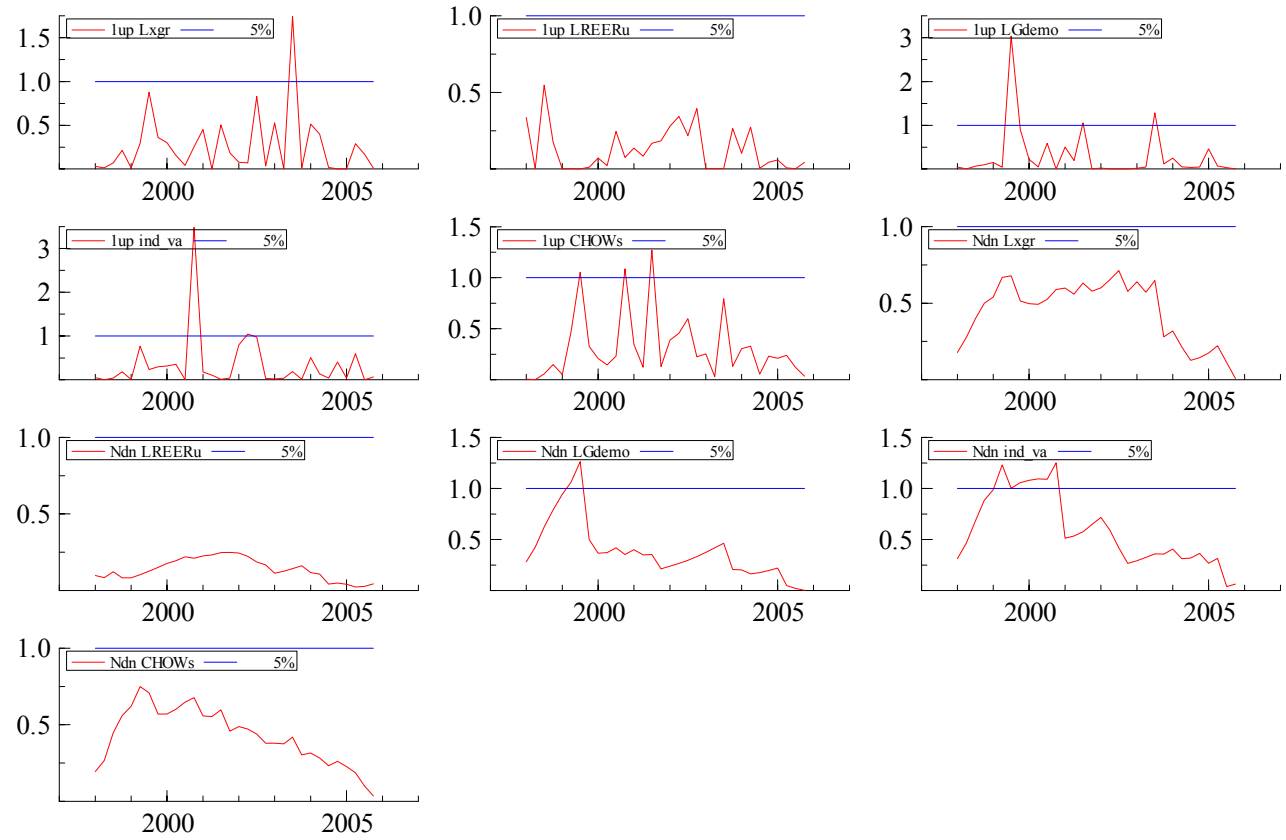
Table 1. Germany: Selected Export Growth Rates and Shares

\begin{tabular}{lcccc}
\hline & $95-00$ & $00-05$ & $95-05$ & $\begin{array}{c}\text { Share of Exports } \\
2005\end{array}$ \\
& & & (In percent) \\
& & (Annual growth rate) & \\
Total exports & 9.3 & 5.6 & 7.4 & 100 \\
Of which 1/ & & & 7.4 & 63.3 \\
European Union & $\ldots$ & $\ldots$ & 6.9 & 43.3 \\
$\quad$ Euro area & $\ldots$ & $\ldots$ & 12.5 & 8.6 \\
EU (new) & $\ldots$ & $\ldots .9$ & 6.3 & 11.0 \\
Asia & 6.2 & 17.6 & 14.5 & 2.7 \\
$\quad$ China & 11.4 & 15.1 & 6.0 & 0.5 \\
$\quad$ India & -2.3 & & & \\
Oil exporters & & 8.9 & 8.3 & 0.5 \\
$\quad$ Saudi Arabia & 7.8 & 14.9 & 13.8 & 0.5 \\
$\quad$ Arab Emirates & 12.8 & 23.1 & 13.9 & 0.5 \\
$\quad$ Iran & 5.4 & & & \\
\hline
\end{tabular}

Source: German Statistical Office.

$1 /$ of which does not add up to total.

Table 2. Summary Statistics 1993Q1-2005Q4 1/

\begin{tabular}{llcc}
\hline & $\mathrm{N}$ & Means & Standard Deviation \\
\hline xgr & 52 & 4.8770 & 0.27603 \\
Reer_ulc & 52 & 4.6711 & 0.07372 \\
Gdem & 52 & 4.4651 & 0.25959 \\
Ginv & 52 & 4.5145 & 0.14991 \\
Dom_VA & 52 & 0.3603 & 0.02057 \\
\hline
\end{tabular}

$1 /$ Variables in log levels

Table 3.A: Standard Export Demand Model Lag Structure and Reduction Tests, sample 1993Q1-2005Q4

\begin{tabular}{ccccccc}
\hline Model & $\mathrm{T}$ & $\mathrm{p}$ & log-likelihood & $\mathrm{SC}$ & $\mathrm{HQ}$ & AIC \\
\hline 1 & 52 & 48 & 499.6372 & -15.57 & -16.68 & -17.371 \\
2 & 52 & 39 & 486.0981 & -15.733 & -16.635 & -17.196 \\
3 & 52 & 30 & 474.9738 & -15.989 & -16.683 & -17.114 \\
4 & 52 & 21 & 446.3374 & -15.571 & -16.057 & -16.359 \\
5 & 52 & 12 & 413.0468 & -14.975 & -15.252 & -15.425 \\
\hline
\end{tabular}


Table 3.B: Export Demand Model Driven by Domestic Investment and Foreign Capital Goods Lag Structure and Reduction Tests, sample 1993Q1-2005Q4

\begin{tabular}{ccccccc}
\hline Model & $\mathrm{T}$ & $\mathrm{p}$ & log-likelihood & $\mathrm{SC}$ & $\mathrm{HQ}$ & AIC \\
\hline 1 & 52 & 48 & 486.6842 & -15.071 & -16.182 & -16.872 \\
2 & 52 & 39 & 478.54 & -15.442 & -16.344 & -16.905 \\
3 & 52 & 30 & 467.2285 & -15.691 & -16.385 & -16.816 \\
4 & 52 & 21 & 447.4903 & -15.615 & -16.101 & -16.403 \\
5 & 52 & 12 & 403.2499 & -14.598 & -14.875 & -15.048 \\
\hline
\end{tabular}

Table 3.C: Combination Standard Export Demand Model and Domestic Investment Driven Model for Lag Structure and Reduction Tests, sample 1993Q1-2005Q4

\begin{tabular}{ccccccc}
\hline Model & $\mathrm{T}$ & $\mathrm{p}$ & log-likelihood & $\mathrm{SC}$ & $\mathrm{HQ}$ & $\mathrm{AIC}$ \\
\hline 1 & 52 & 96 & 789.9447 & -23.088 & -25.309 & -26.69 \\
2 & 52 & 80 & 768.0534 & -23.462 & -25.313 & -26.464 \\
3 & 52 & 64 & 755.8452 & -24.208 & -25.689 & -26.609 \\
4 & 52 & 48 & 715.1765 & -23.859 & -24.97 & -25.661 \\
5 & 52 & 32 & 661.04775 & -22.993 & -23.734 & -24.194 \\
\hline
\end{tabular}

Table 3.D: Export Demand Model Driven by Regionalization of Production Processes, Model for Lag Structure and Reduction Tests, sample 1993Q1-2005Q4

\begin{tabular}{crrrrrr}
\hline $\begin{array}{c}\text { Model } \\
1\end{array}$ & $\mathrm{~T}$ & $\mathrm{p}$ & log-likelihood & $\mathrm{SC}$ & $\mathrm{HQ}$ & $\mathrm{AIC}$ \\
& 52 & 96 & $742.8686-21.277$ & -23.499 & -24.88 \\
2 & 52 & 80 & $716.8998-21.494$ & -23.345 & -24.496 \\
3 & 52 & 64 & 710.147 & -22.45 & -23.931 & -24.852 \\
4 & 52 & 48 & $670.0764-22.125$ & -23.235 & -23.926 \\
& & & & & & \\
5 & 52 & 32 & $642.1267-22.266$ & -23.006 & -23.466 \\
\hline
\end{tabular}


Table 4.A: Standard Export Demand Model Lag

Structure and Reduction Tests, Sample 1993Q1-2005Q4

Unrestricted Models

\begin{tabular}{|c|c|c|c|c|}
\hline $\begin{array}{c}\text { Restricted } \\
\text { Lags }\end{array}$ & 5 & 4 & 3 & 2 \\
\hline 4 & $\begin{array}{c}2.1975 \\
{[0.0303]^{*}}\end{array}$ & & & \\
\hline 3 & $\begin{array}{c}2.1396 \\
{[0.0096]^{* *}}\end{array}$ & $\begin{array}{c}1.9263 \\
{[0.0580]}\end{array}$ & & \\
\hline 2 & $\begin{array}{c}3.7668 \\
{[0.0000]^{* *}}\end{array}$ & $\begin{array}{c}4.1889 \\
{[0.0000]^{* *}}\end{array}$ & $\begin{array}{c}6.2002 \\
{[0.0000]^{* *}}\end{array}$ & \\
\hline 1 & $\begin{array}{c}5.8658 \\
{[0.0000]^{\star *}}\end{array}$ & $\begin{array}{c}6.5102 \\
{[0.0000]^{\star *}}\end{array}$ & $\begin{array}{c}8.3400 \\
{[0.0000]^{\star *}}\end{array}$ & $\begin{array}{c}8.0619 \\
{[0.0000]^{\star *}}\end{array}$ \\
\hline
\end{tabular}

Table 4.B: Export Demand Model Driven by Domestic Investment and Foreign Capital Goods Model

Reduction Tests: Lag Length and Specification of the VAR

\begin{tabular}{ccccc}
\hline \multicolumn{5}{c}{ Unrestricted Models } \\
\hline $\begin{array}{c}\text { Restricted } \\
\text { Lags }\end{array}$ & $\mathbf{5}$ & $\mathbf{4}$ & $\mathbf{3}$ & $\mathbf{2}$ \\
& 1.2652 & & & \\
$\mathbf{4}$ & {$[0.2684]$} & & & \\
& 1.6262 & 1.9617 & & \\
$\mathbf{3}$ & {$[0.0685]$} & {$[0.0531]$} & & \\
& 2.5007 & 3.0685 & 3.9657 & \\
$\mathbf{2}$ & {$[0.0005]^{* *}$} & {$[0.0002]^{* *}$} & {$[0.0002]^{* *}$} & \\
& 5.5165 & 6.8254 & 8.7546 & 11.785 \\
$\mathbf{1}$ & {$[0.0000]^{* *}$} & {$[0.0000]^{* *}$} & {$[0.0000]^{* *}$} & {$[0.0000]^{* *}$} \\
\hline
\end{tabular}


Table 4.C: Combination Standard Export Demand Model and Domestic Investment Driven Model for Foreign Capital Goods Model Reduction Tests: Lag Length and Specification of the VAR

\begin{tabular}{ccccc}
\hline \multirow{5}{*}{$\begin{array}{c}\text { Unrestricted Models } \\
\text { Restricted } \\
\text { Lags }\end{array}$} & 5 & 4 & 3 & 2 \\
\hline $\mathbf{4}$ & 1.5274 & & & \\
& {$[0.1117]$} & & & \\
$\mathbf{3}$ & 1.2518 & 0.92656 & & \\
& {$[0.2026]$} & {$[0.5423]$} & & \\
$\mathbf{2}$ & 2.2734 & 2.4958 & 4.2397 \\
& {$[0.0003]^{* *}$} & {$[0.0002]^{\star *}$} & {$[0.0000]^{* *}$} & 6.9395 \\
$\mathbf{1}$ & 3.9870 & 4.5280 & 6.5025 & {$[0.0000]^{*}$} \\
& {$[0.0000]^{* *}$} & {$[0.0000]^{\star *}$} & {$[0.0000]^{* *}$} & ${ }^{*}$ \\
\hline
\end{tabular}

Table 4.D: Export Demand Model Driven by Regionalization of Production Processes, Model Reduction Tests: Lag Length and Specification of the VAR

\begin{tabular}{ccccc}
\hline & \multicolumn{5}{c}{ Unrestricted Models } \\
$\begin{array}{c}\text { Restricted } \\
\text { Lags }\end{array}$ & $\mathbf{5}$ & $\mathbf{4}$ & $\mathbf{3}$ & $\mathbf{2}$ \\
\hline \multirow{2}{*}{$\mathbf{4}$} & 1.8614 & & & \\
& {$[0.0376]^{*}$} & & & \\
$\mathbf{3}$ & 1.1921 & 0.49487 & & \\
& {$[0.2549]$} & {$[0.9437]$} & & \\
$\mathbf{2}$ & 2.1890 & 2.1356 & 4.1603 & \\
& {$[0.0005]^{* *}$} & {$[0.0020]^{* *}$} & {$[0.0000]^{* *}$} & \\
$\mathbf{1}$ & 2.6454 & 2.6299 & 3.9792 & 2.9962 \\
& {$[0.0000]^{* *}[0.0000]^{* *}[0.0000]^{* *}[0.0004]^{* *}$} \\
\hline \multicolumn{5}{c}{}
\end{tabular}


Table 5.A: Individual Equation and Vector Misspecification Tests for the Standard Export Demand Model

\begin{tabular}{lllc} 
Lxgr & Portmanteau( 6): & & \\
LREERu & Portmanteau( 6): & & 3.65372 \\
LGdem & Portmanteau( 6): & & 1.20985 \\
& & & 8.20337 \\
Lxgr & AR 1-4 test: & $\mathrm{F}(4,32)$ & $1.7037[0.1735]$ \\
LREERu & AR 1-4 test: & $\mathrm{F}(4,32)$ & $0.34946[0.8424]$ \\
LGdem & AR 1-4 test: & $\mathrm{F}(4,32)$ & $1.3315[0.2796]$ \\
& & & \\
Lxgr & Normality test: & $\mathrm{Chi}^{\wedge} 2(2)$ & $0.83290[0.6594]$ \\
LREERu & Normality test: & $\mathrm{Chi}{ }^{\wedge} 2(2)$ & $0.75053[0.6871]$ \\
LGdem & Normality test: & $\mathrm{Chi}{ }^{\wedge} 2(2)$ & $2.5739[0.2761]$ \\
& & & \\
Lxgr & ARCH 1-4 test: & $\mathrm{F}(4,28)$ & $0.41948[0.7932]$ \\
LREERu & ARCH 1-4 test: & $\mathrm{F}(4,28)$ & $0.07348[0.9896]$ \\
LGdem & ARCH 1-4 test: & $\mathrm{F}(4,28)$ & $1.5709[0.2095]$ \\
& & & \\
Lxgr & hetero test: & $\mathrm{F}(30,5)$ & $0.23698[0.9949]$ \\
LREERu & hetero test: & $\mathrm{F}(30,5)$ & $0.27972[0.9882]$ \\
LGdem & hetero test: & $\mathrm{F}(30,5)$ & $0.16732[0.9994]$ \\
& & & \\
\hline $\begin{array}{l}\text { Vector Portmanteau( 6): } \\
\text { Vector AR 1-4 test: }\end{array}$ & $\mathrm{F}(36,65)$ & $0.9493[0.5586]$ \\
Vector Normality test: & $\mathrm{Chi}{ }^{\wedge} 2(6)$ & $3.3193[0.7678]$ \\
Vector hetero test: & $\mathrm{F}(180,8)$ & $0.0618[1.0000]$ \\
\hline \hline
\end{tabular}




\begin{tabular}{|c|c|c|c|}
\hline \multicolumn{4}{|c|}{$\begin{array}{l}\text { Table 5.B: Individual Equation and Vector Misspecification } \\
\text { Tests for the Export Demand Model Driven by Domestic } \\
\text { Investment and Foreign Capital Goods }\end{array}$} \\
\hline Lxgr & Portmanteau( 6): & & 3.04837 \\
\hline LREERu & Portmanteau( 6): & & 3.47482 \\
\hline LGinv & Portmanteau( 6): & & 1.81366 \\
\hline Lxgr & AR 1-4 test: & $\mathrm{F}(4,35)$ & $1.5220[0.2171]$ \\
\hline LREERu & AR 1-4 test: & $F(4,35)$ & $1.5582[0.2071]$ \\
\hline LGinv & AR 1-4 test: & $\mathrm{F}(4,35)$ & 0.2548 [0.9047] \\
\hline Lxgr & Normality test: & $\mathrm{Chi}^{\wedge} 2(2)$ & $0.7828[0.6761]$ \\
\hline LREERu & Normality test: & $\operatorname{Chi}^{\wedge} 2(2)$ & $5.1559[0.0759]$ \\
\hline LGinv & Normality test: & $\mathrm{Chi}^{\wedge} 2(2)$ & $4.8700[0.0876]$ \\
\hline Lxgr & ARCH 1-4 test: & $\mathrm{F}(4,31)$ & 0.6602 [0.6243] \\
\hline LREERu & ARCH 1-4 test: & $\mathrm{F}(4,31)$ & 0.0793 [0.9881] \\
\hline LGinv & ARCH 1-4 test: & $\mathrm{F}(4,31)$ & 0.0303 [0.9981] \\
\hline Lxgr & hetero test: & $\mathrm{F}(24,14)$ & 0.4162 [0.9715] \\
\hline LREERu & hetero test: & $F(24,14)$ & 0.2573 [0.9983] \\
\hline LGinv & hetero test: & $\mathrm{F}(24,14)$ & 1.0370 [0.4867] \\
\hline \multicolumn{2}{|c|}{ Vector Portmanteau( 6): } & & 38.501 \\
\hline \multicolumn{2}{|c|}{ Vector AR 1-4 test: } & $F(36,74)$ & 1.4589 [0.0859] \\
\hline \multicolumn{2}{|c|}{ Vector Normality test: } & $\mathrm{Chi}^{\wedge} 2(6)$ & 9.8826 [0.1297] \\
\hline \multicolumn{2}{|c|}{ Vector hetero test: } & $F(144,60)$ & 0.4663 [0.9999] \\
\hline
\end{tabular}


Table 5.C: Individual Equation and Vector

Misspecification Tests for the Combination Standard

Export Demand Model and Domestic Investment Driven

Model for Foreign Capital Goods Model

\begin{tabular}{|c|c|c|c|}
\hline Lxgr & Portmanteau( 6): & & 4.37266 \\
\hline LREERu & Portmanteau( 6): & & 0.90127 \\
\hline LGdem & Portmanteau( 6): & & 5.5163 \\
\hline LGinv & Portmanteau( 6): & & 1.71595 \\
\hline Lxgr & AR 1-4 test: & $\mathrm{F}(2,34)$ & $0.5542[0.6976]$ \\
\hline LREERu & AR 1-4 test: & $\mathrm{F}(2,34)$ & $0.8249[0.5205]$ \\
\hline LGdem & AR 1-4 test: & $\mathrm{F}(2,34)$ & $3.4265[0.0212]^{*}$ \\
\hline LGinv & AR 1-4 test: & $\mathrm{F}(2,34)$ & $3.9476[0.0115]^{*}$ \\
\hline Lxgr & Normality test: & $\mathrm{Chi}^{\wedge} 2(2)$ & $1.0763[0.5838]$ \\
\hline LREERu & Normality test: & $\mathrm{Chi}^{\wedge} 2(2)$ & $5.0892[0.0785]$ \\
\hline LGdem & Normality test: & $\mathrm{Chi}^{\wedge} 2(2)$ & $2.6014[0.2723]$ \\
\hline LGinv & Normality test: & $\mathrm{Chi}^{\wedge} 2(2)$ & $0.39522[0.8207]$ \\
\hline Lxgr & ARCH 1-4 test: & $\mathrm{F}(1,34)$ & $0.38557[0.8168]$ \\
\hline LREERu & ARCH 1-4 test: & $\mathrm{F}(1,34)$ & $0.10243[0.9806]$ \\
\hline LGdem & ARCH 1-4 test: & $\mathrm{F}(1,34)$ & $0.79815[0.5382]$ \\
\hline LGinv & ARCH 1-4 test: & $\mathrm{F}(1,34)$ & 1.0559 [0.3997] \\
\hline Lxgr & hetero test: & $\mathrm{F}(18,17)$ & $25.775[0.7735]$ \\
\hline LREERu & hetero test: & $\mathrm{F}(18,17)$ & $37.524[0.2307]$ \\
\hline LGdem & hetero test: & $\mathrm{F}(18,17)$ & $40.301[0.1489]$ \\
\hline LGinv & hetero test: & $\mathrm{F}(18,17)$ & $46.030[0.0517]$ \\
\hline \multicolumn{3}{|c|}{ Vector Portmanteau( 6): } & 80.1506 \\
\hline \multicolumn{2}{|c|}{ Vector AR 1-2 test: } & $\mathrm{F}(32,93)$ & $1.9499[0.0067]^{* *}$ \\
\hline \multicolumn{2}{|c|}{ Vector Normality test: } & $\mathrm{Chi}^{\wedge} 2(8)$ & 11.383 [0.1809] \\
\hline \multicolumn{2}{|c|}{ Vector hetero test: } & $\mathrm{F}(180,91)$ & $341.38[0.1968]$ \\
\hline
\end{tabular}


Table 5.D: Individual Equation and Vector Misspecification Tests for the Export Demand Model Driven by Regionalization of Production Processes

Lxgr Portmanteau( 6): $\quad 2.82619$

LREERuPortmanteau( 6): $\quad 1.00148$

LGdem Portmanteau( 6): $\quad 7.62194$

ind_va Portmanteau( 6): $\quad 1.37764$

Lxgr $\quad$ AR 1-4 test: $\quad \mathrm{F}(2,34) \quad 0.10128$ [0.9812]

LREERuAR 1-4 test: $\quad \mathrm{F}(2,34) \quad 0.25279$ [0.9058]

LGdem AR 1-4 test: $\quad \mathrm{F}(2,34) \quad 4.5998$ [0.0048]*

ind_va AR 1-4 test: $\quad \mathrm{F}(2,34) \quad 0.15007$ [0.9616]

Lxgr Normality test: $\mathrm{Chi}^{\wedge} 2$ (2) 0.49661 [0.7801]

LREERuNormality test: $\mathrm{Chi}^{\wedge} 2$ (2) 5.3022 [0.0706]

LGdem Normality test: $\mathrm{Chi}^{\wedge} 2$ (2) 0.12052 [0.9415]

ind_va Normality test: $\mathrm{Chi}^{\wedge} 2$ (2) 2.3650 [0.3065]

Lxgr ARCH 1-4 test: $F(24,11) 0.9640$ [0.4426]

LREERuARCH 1-4 test: F(24,11) 0.2631 [0.8991]

LGdem ARCH 1-4 test: F(24,11) 2.035 [0.1166]

ind_va ARCH 1-4 test: $\mathrm{F}(24,11) 0.3338$ [0.8528]

Lxgr hetero test: $\quad F(18,17) 0.26675[0.9967]$

LREERuhetero test: $\quad \mathrm{F}(18,17) 0.64676[0.8206]$

LGdem hetero test: $\quad F(18,17) 0.62324[0.8393]$

ind_va hetero test: $\quad \mathrm{F}(18,17) 0.50927[0.9191]$

Vector Portmanteau( 6): $\quad 67.044$

Vector AR 1-4 test: $\quad \mathrm{F}(64,68) 1.2482$ [0.1842]

Vector Normality test: $\quad$ Chi^$^{\wedge} 2(8) 10.620$ [0.2242]

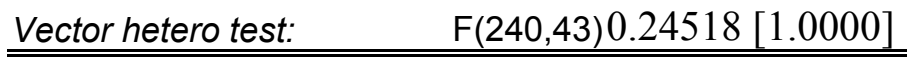


Table 6.A: Standard Export Demand Model

Cointegration Analysis with Johansen Test: sample 1993Q1-2005Q4

\begin{tabular}{|c|c|c|c|c|c|c|}
\hline H0:rank & eigenvalue & loglik for & $\begin{array}{c}\text { Trace test } \\
\text { [ Prob] }\end{array}$ & $\begin{array}{c}\text { Max test } \\
\text { [ Prob] }\end{array}$ & $\begin{array}{l}\text { Trace test } \\
\text { (T-nm) }\end{array}$ & $\begin{array}{c}\text { Max test } \\
\text { (T-nm) }\end{array}$ \\
\hline & & 484.3679 & & & & \\
\hline 0 & 0.26591 & 492.4053 & $\begin{array}{l}30.54 \\
{[0.041]^{*}} \\
14.46\end{array}$ & $\begin{array}{l}16.07 \\
{[0.229]} \\
12.53\end{array}$ & $\begin{array}{l}21.73 \\
{[0.324]} \\
10.29\end{array}$ & $\begin{array}{l}11.44 \\
{[0.614]} \\
8.91\end{array}$ \\
\hline 1 & $\begin{array}{r}0.21409 \\
0.036556\end{array}$ & $\begin{array}{l}498.6689 \\
499.6372\end{array}$ & $\begin{array}{c}{[0.070]} \\
1.94 \\
{[0.164]}\end{array}$ & $\begin{array}{c}{[0.092]} \\
1.94 \\
{[0.164]}\end{array}$ & $\begin{array}{c}{[0.264]} \\
1.38 \\
{[0.240]}\end{array}$ & $\begin{array}{c}{[0.300]} \\
1.38 \\
{[0.240]}\end{array}$ \\
\hline
\end{tabular}

Reduced Rank Standardized Coefficients

\begin{tabular}{lrrrr}
\hline & \multicolumn{1}{l}{$\begin{array}{l}\text { Beta } \\
\text { Vector }\end{array}$} & \multicolumn{1}{c}{ Std Err } & \multicolumn{2}{l}{$\begin{array}{l}\text { Alpha } \\
\text { Vector }\end{array}$} \\
Lxgr & 1 & 0 & -0.51799 & Std Err \\
LREERu & 0.16791 & 0.11838 & 0.28222 & 0.15061 \\
LGdem & -1.0584 & 0.030943 & -0.01167 & 0.02797
\end{tabular}

Hypotheses Tests for the Beta Vector

\begin{tabular}{llll}
\hline LREERu & Zero & $\mathrm{Chi}^{\wedge} 2(1)$ & $0.4505[0.5021]$ \\
LGdem & Zero & $\mathrm{Chi}^{\wedge} 2(1)$ & $3.5376[0.0600]$ \\
LREERu and LGdem & Zero & $\mathrm{Chi}^{\wedge} 2(2)$ & $9.0188[0.0110]^{*}$ \\
& Unit & & \\
LGdem & Elastic & $\mathrm{Chi}^{\wedge} 2(1)$ & $2.7530[0.0971]$
\end{tabular}

Hypotheses Tests for the Alpha Vector: Weak Exogeneity

\begin{tabular}{|c|c|c|c|}
\hline Lxgr & Zero & $\mathrm{Chi}^{\wedge} 2(1)$ & $3.2877[0.0698]$ \\
\hline LREERu & Zero & $\mathrm{Chi}^{\wedge} 2(1)$ & $1.7550[0.1852]$ \\
\hline LGdem & Zero & $\mathrm{Chi}^{\wedge} 2(1)$ & 0.0757 [0.7832] \\
\hline LREERu and LGdem & Zero & $\mathrm{Chi}^{\wedge} 2(2)$ & $2.6166[0.2703]$ \\
\hline
\end{tabular}

Joint Hypothesis Test: W.E and Unit Elasticity

$\mathrm{Chi}^{\wedge} 2(3) \quad 3.8190[0.2817]$

Final Reduced Rank Cointegrating Relation

\begin{tabular}{lrrrr} 
& \multicolumn{1}{l}{ Beta } & & Alpha & \\
& Vector & Std Err & Vector & Std Err \\
Lxgr & 1 & & -0.62753 & 0.19348 \\
LREERu & 0.41898 & 0.096262 & & \\
LGdem & -1 & & & \\
\hline \hline
\end{tabular}

P-values are in brackets. 
Table 6.B: Export Demand Model

Driven by Domestic Investment and Foreign Capital Goods

Cointegration Analysis with Johansen Test: sample 1993Q1-2005Q4

\begin{tabular}{rrrrrrl} 
H0:rank & eigenvalue & loglik for & $\begin{array}{c}\text { Trace test } \\
{[\text { Prob] }}\end{array}$ & $\begin{array}{c}\text { Max test } \\
\text { Prob] }\end{array}$ & $\begin{array}{c}\text { Trace test } \\
(\text { T-nm })\end{array}$ & $\begin{array}{c}\text { Max test } \\
(\text { T-nm) }\end{array}$ \\
\hline & & 470.2091 & & & & \\
& & & 16.66 & 11.04 & 12.82 & 8.49 \\
0 & 0.19128 & 475.7288 & {$[0.672]$} & {$[0.652]$} & {$[0.897]$} & {$[0.865]$} \\
& & & 5.62 & 5.56 & 4.32 & 4.28 \\
1 & 0.10137 & 478.5079 & {$[0.741]$} & {$[0.674]$} & {$[0.871]$} & {$[0.824]$} \\
& & & 0.06 & 0.06 & 0.05 & 0.05 \\
2 & 0.0012351 & 478.54 & {$[0.800]$} & {$[0.800]$} & {$[0.824]$} & {$[0.824]$} \\
\hline \hline
\end{tabular}

P-values in brackets 


\begin{tabular}{|c|c|c|c|c|c|c|}
\hline \multicolumn{7}{|c|}{$\begin{array}{l}\text { Table 6.C: Combination of the Standard Export Demand Model and Domestic Investment Driven } \\
\text { Model for Foreign Capital Goods Model }\end{array}$} \\
\hline \multicolumn{7}{|c|}{$\begin{array}{c}\text { Cointegration Analysis with Johansen Test: sample 1993q1-2005q4 } \\
\end{array}$} \\
\hline H0:rank & igenvalue & loglik for & $\begin{array}{c}\text { Trace test } \\
{[\text { Prob] }}\end{array}$ & $\begin{array}{r}\text { Max test }[ \\
\text { Prob] }\end{array}$ & $\begin{array}{l}\text { Trace test } \\
(\mathrm{T}-\mathrm{nm})\end{array}$ & $\begin{array}{l}\text { Max test } \\
(\mathrm{T}-\mathrm{nm})\end{array}$ \\
\hline \multicolumn{7}{|c|}{754.3154} \\
\hline 0 & 0.4156 & 768.2819 & $\begin{array}{l}71.26 \\
{[0.000]^{* *}} \\
43.33\end{array}$ & $\begin{array}{l}27.93 \\
{[0.042]^{*}} \\
21.83\end{array}$ & $\begin{array}{l}43.85 \\
{[0.113]} \\
26.66\end{array}$ & $\begin{array}{l}17.19 \\
{[0.574]}\end{array}$ \\
\hline \multirow[t]{2}{*}{1} & 0.3428 & 779.1958 & {$[0.001]^{* *}$} & {$[0.038]^{*}$} & [0.113] & [0.428] \\
\hline & & & 21.50 & 17.34 & 13.23 & 10.67 \\
\hline \multirow[t]{2}{*}{2} & 0.2835 & 787.8634 & {$[0.005]^{* *}$} & {$[0.014]^{*}$} & [0.107] & {$[0.174]$} \\
\hline & & & 4.16 & 4.16 & 2.56 & 2.56 \\
\hline \multirow[t]{2}{*}{3} & 0.07693 & 789.9447 & {$[0.041]^{*}$} & {$[0.041]^{*}$} & [0.109] & [0.109] \\
\hline & \multicolumn{5}{|c|}{ Reduced Rank Standardized Coefficients } & \\
\hline \multicolumn{2}{|r|}{ Beta Vector } & Std Err & Alpha Vector & \multicolumn{2}{|l|}{ Std Err } & \\
\hline Lxgr & 1 & 0 & -0.09193 & \multicolumn{2}{|l|}{0.11938} & \\
\hline LREERu & 0.32276 & 0.1723 & -0.13943 & \multicolumn{2}{|l|}{0.09714} & \\
\hline LGdem & -3.2322 & 0.47444 & 0.01553 & \multicolumn{2}{|l|}{0.017387} & \\
\hline LGinv & 3.8936 & 0.80453 & -0.025409 & \multicolumn{2}{|l|}{0.016441} & \\
\hline \multicolumn{7}{|c|}{ Hypotheses Tests for the Beta Vector } \\
\hline LREERu & & Zero & $\mathrm{Chi}^{\wedge} 2(1)$ & \multicolumn{2}{|c|}{$2.1735[0.1404]$} & \\
\hline LGdem & & Zero & $\mathrm{Chi}^{\wedge} 2(1)$ & \multicolumn{2}{|c|}{$4.3830[0.0363]^{*}$} & \\
\hline LGinv & & $\begin{array}{l}\text { Zero } \\
\text { Unit }\end{array}$ & $\mathrm{Chi}^{\wedge} 2(1)$ & \multicolumn{2}{|c|}{$5.3425[0.0208]^{*}$} & \\
\hline All three & & Elastic & $\mathrm{Chi}^{\wedge} 2(3)$ & \multicolumn{2}{|c|}{$9.9190[0.0193]^{*}$} & \\
\hline LGdem - LGinv & & Zero & $\mathrm{Chi}^{\wedge} 2(1)$ & \multicolumn{2}{|c|}{$1.3189[0.2508]$} & \\
\hline \multicolumn{7}{|c|}{ Hypotheses Tests for the Alpha Vector: Weak Exogeneity } \\
\hline Lxgr & & Zero & $\mathrm{Chi}^{\wedge} 2(1)$ & \multicolumn{2}{|c|}{$0.4498[0.5024]$} & \\
\hline LREERu & & Zero & $\mathrm{Chi}^{\wedge} 2(1)$ & \multicolumn{2}{|c|}{$2.1607[0.1416]$} & \\
\hline LGdem & & Zero & $\mathrm{Chi}^{\wedge} 2(1)$ & \multicolumn{2}{|c|}{$0.3826[0.5362$} & \\
\hline LGinv & & Zero & $\mathrm{Chi}^{\wedge} 2(1)$ & \multicolumn{2}{|c|}{$1.1924[0.2748]$} & \\
\hline All three & & Zero & $\operatorname{Chi}^{\wedge} 2(3)$ & \multicolumn{2}{|c|}{$9.7032[0.0213]^{*}$} & \\
\hline Lxgr and LREER & & Zero & $\mathrm{Chi}^{\wedge} 2(2)$ & \multicolumn{2}{|c|}{$3.5841[0.1666]$} & \\
\hline & Joi & it Hypothesis & Test: W.E anc & Unit Elasticity & & \\
\hline LGdem - LGinv & & & $\mathrm{Chi}^{\wedge} 2(3)$ & $6.2446[0.100$ & & \\
\hline Lxgr and LREER & & & & & & \\
\hline & & nal Reduced & Rank Cointegr & tting Relation & & \\
\hline & Beta Vector & Std Err & Alpha Vector & Std Err & & \\
\hline Lxgr & 1 & 0 & -0.32908 & 0.19329 & & \\
\hline LREERu & 0.26671 & 0.099982 & -0.17368 & 0.16532 & & \\
\hline LGdem & -2.3574 & 0 & 0.012693 & 0.029446 & & \\
\hline LGinv & 2.3574 & 0.059901 & -0.044729 & 0.027463 & & \\
\hline
\end{tabular}




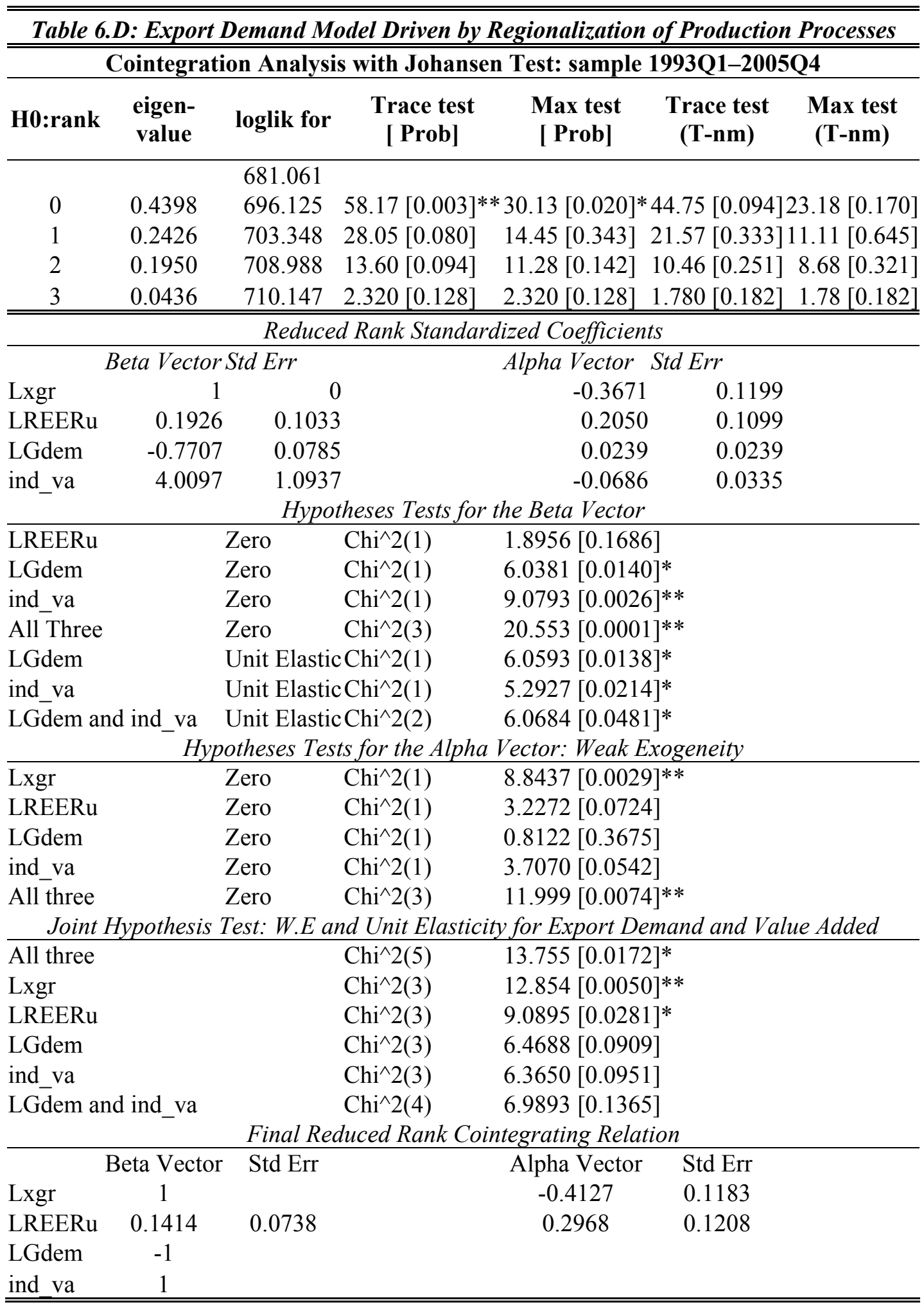


Table 7. Export growth and explanatory value of variables

\begin{tabular}{|c|c|c|c|c|c|c|c|c|}
\hline & \multicolumn{3}{|c|}{ Export growth } & \multicolumn{3}{|c|}{ Global demand } & \multirow[t]{2}{*}{ Reer_ulc } & \multirow[t]{2}{*}{ DomVA } \\
\hline & Actual & Model & Residual & Total & $\begin{array}{l}\text { Ind cntr } \\
\text { common }\end{array}$ & $\begin{array}{l}\text { German } \\
\text { specifc }\end{array}$ & & \\
\hline & \multicolumn{8}{|c|}{ (Average annual growth rate) } \\
\hline \multirow[t]{2}{*}{ Model D } & 6.01 & 5.00 & 1.01 & 3.92 & 3.22 & 0.71 & 0.11 & 0.97 \\
\hline & & \multicolumn{7}{|c|}{ Percent of export growth explained by } \\
\hline \multirow[t]{2}{*}{ Model D } & & 83.2 & 16.8 & 65.3 & 53.5 & 11.8 & 1.8 & 16.1 \\
\hline & & & \multicolumn{6}{|c|}{ Percent of market share increase explained by } \\
\hline Model D & & $\ldots$ & 36.2 & $\ldots$ & $\ldots$ & 25.3 & 3.9 & 34.7 \\
\hline \multicolumn{9}{|c|}{$\begin{array}{l}\text { Memorandum items } \\
\text { Long run parameters }\end{array}$} \\
\hline Model D & & $\ldots$ & $\ldots$ & 0.7707 & 0.7707 & 0.7707 & -0.1926 & -4.0097 \\
\hline
\end{tabular}

